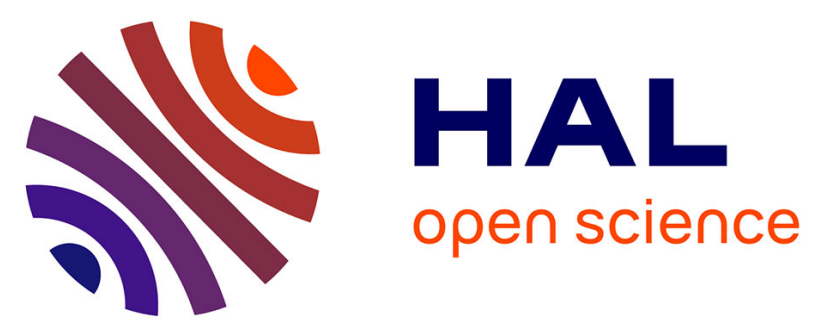

\title{
Mandatory Integrated Pest Management in the European Union: Experimental insights on consumers' reactions
}

\author{
Marianne Lefebvre, C. Biguzzi, E. Ginon, S. Gomez-Y-Paloma, S. R H \\ Langrell, S. Marette, G. Mateu, A. Sutan
}

\section{To cite this version:}

Marianne Lefebvre, C. Biguzzi, E. Ginon, S. Gomez-Y-Paloma, S. R H Langrell, et al.. Mandatory Integrated Pest Management in the European Union: Experimental insights on consumers' reactions. Review of Agricultural, Food and Environmental Studies, 2017, 98 (1-2), pp.25-54. 10.1007/s41130017-0041-x . hal-02519085

\section{HAL Id: hal-02519085 \\ https://univ-angers.hal.science/hal-02519085}

Submitted on 25 Mar 2020

HAL is a multi-disciplinary open access archive for the deposit and dissemination of scientific research documents, whether they are published or not. The documents may come from teaching and research institutions in France or abroad, or from public or private research centers.
L'archive ouverte pluridisciplinaire HAL, est destinée au dépôt et à la diffusion de documents scientifiques de niveau recherche, publiés ou non, émanant des établissements d'enseignement et de recherche français ou étrangers, des laboratoires publics ou privés. 


\title{
Mandatory Integrated Pest Management in the European Union: Experimental insights on consumers' reactions
}

\author{
M. Lefebvre ${ }^{1,2}$, C. Biguzzi ${ }^{3}$, E. Ginon ${ }^{3}$, S. Gomez-y-Paloma ${ }^{1}$, S. R. H. Langrell ${ }^{4}$, S. Marette ${ }^{5}$, G. \\ Mateu $^{3}$, A. Sutan ${ }^{3}$
}

1 European Commission, Directorate General Joint Research Centre (JRC), Institute for Prospective Technological Studies (IPTS), Agriculture in the Economy Unit, Edificio Expo. c/ Inca Garcilaso, 3, ES-41092 Seville, Spain

2 Université d'Angers, UMR Granem, F-49000, France orcid.org/0000-0003-2876-1226

3 Laboratory for Experimentation in Social Sciences and Behavioral Analysis (LESSAC), Burgundy School of Business, F-21000 Dijon, France

4 European Commission, DG Health and Food Safety, Directorate F- Health and food audits and analysis, Plants and organics (F.3), Plant health and GMO Sector, Grange, Dunsany Co. Meath, Ireland 5 INRA, UMR Economie Publique, F-78850 Thiverval-Grignon, France

Corresponding author: marianne.lefebvre@univ-angers.fr

\begin{abstract}
A realistic experiment with 189 French consumers was conducted to analyse consumers' reaction to the transition towards Integrated Pest Management (IPM) as the standard in European farming. Results indicate high substitutability between IPM and organic tomatoes. It suggests IPM sales will benefit from the withdrawal of conventional products from the market only if there is a significant reduction in the price of IPM products as compared to organic ones and/or an important increase in the shelf space dedicated to IPM products. While information on IPM guidelines increases IPM products purchases, providing extra information on residue levels in IPM tomatoes has no further impact on consumers' choices in this experiment.
\end{abstract}

JEL code: C91, D12, Q13, Q18

Keywords: Integrated Pest Management, Organic, Tomatoes, Sustainable Use of pesticides Directive, Multinomial probit, Open-ended Choice Experiment 


\section{Acknowledgments and disclaimer:}

The survey on which this paper is based was funded by the IPTS, JRC-European Commission in the context of the project "Consumers' willingness to pay for Integrated Production: experimental design and data collection", PO 153580. However, the views expressed are purely those of the authors and may not in any circumstances be regarded as stating an official position of the European Commission. Marianne Lefebvre acknowledges funding from Agropolis Fondation and the French National Research Agency (program "Investissements d'avenir" ANR-10-LABX-0001-01, Project "CAP-eye"). The authors would like to thank the partners of the FP7-PURE project for supporting the initial idea. We would especially like to thank Christine Poncet (INRA) for contributing to the elaboration of the information on the different types of tomatoes disclosed to participants. We are also grateful to the two anonymous referees for their constructive input.

M. Lefebvre, S. R. H. Langrell and S. Gomez y Paloma formulated the original question. The experiment was designed by E. Ginon, S. Marette, and A. Sutan with the help of M. Lefebvre and G. Mateu and programmed by G. Mateu in z-Tree. The sessions were organized by C. Biguzzi with the help of E. Ginon, G. Mateu, A. Sutan and H. Saysithideth. M. Lefebvre performed data analysis and wrote the first version of the manuscript. All authors provided feedback on previous versions of the manuscript. M. Lefebvre was responsible for overall coordination. 


\section{Introduction}

Many scientific and regulatory claims have been made over recent years about the potential harmful effects of pesticide intensive farming systems for both environment and human health (Aubertot et al. 2005). The search for sustainability of agriculture has led to explore potential alternatives to crop protection and to the adoption by the European Union (EU) in 2009 of the Sustainable Use of pesticides Directive (SUD). This directive provides a framework for action to achieve a sustainable use of pesticides and to promote the adoption of low pesticide input pest management. Integrated Pest Management (IPM) has been retained as one of the possible approaches to achieve low pesticide-input pest management in the EU, together with organic farming (EU 2009). As described in the SUD, IPM is a system based on three main principles: i) the use and integration of measures that discourage the development of populations of harmful organisms; ii) the careful consideration of all available plant protection methods, including: biological, mechanical and chemical control; and iii) the use of chemical control to levels that are economically and ecologically justified. This possible application of chemical pesticides helps to bypass the problem of low yields linked to organic farming, leading to more affordable products. As a result, IPM has been described as "a middle course between the extreme constraints of organic farming standards and the increasingly unacceptable pursuit of intensive agriculture" (Wibberley 1995), and as "a third way, both economically realistic and environmentally beneficial" (Morris and Winter 1999).

Whilst consumers' willingness to pay (WTP), and preferences for organic food products, have been widely considered and confirmed in the literature (Aertsens et al. 2009; Wier and Calverley 2002; Yiridoe, Bonti-Ankomah, and Martin 2002), the knowledge of the IPM market is much more limited. Do consumers recognize the benefits of this "third way"? Widespread adoption of IPM by farmers will depend, among other drivers, on the profitability of this crop protection strategy (Lefebvre, Langrell and Gomez-y-Paloma 2015). Predicting the proportion of consumers in the market who will select IPM products, when other products are available, is a key question. Consequently, this article aims at analysing consumers' preferences for IPM in the presence of both conventional and organic products.

Marketing IPM products for the end-consumer is neither a simplistic nor straightforward task, for several reasons. First, pest control based on economic thresholds and decision models appears difficult to communicate since there is no clear commitment regarding the reduction in overall pesticides use. Second, given the varieties of principles covered by the term "IPM" (as illustrated by the list of general principles of IPM in the Annex III of the SUD), there is a risk of multiplication of labels, with quite different interpretations and approaches. Finally, such a situation may add to the possible market saturation of certification schemes and labels that may lead to an information overload for end-consumers. Producers are encouraged to apply to different certifications for the same product in order to have access to different market segments, resulting in increased production costs whilst, simultaneously, further contributing to consumer confusion (Canali 2011). The large number of different logos indicating environmental sustainability already available in the market raises the question of whether their associated messages are successfully conveyed to consumers. Previous research has shown that 
most existing logos fail to convey their message, which suggests the need to provide consumers with adequate information on environmental sustainability (Ginon et al. 2014).

These different arguments may explain why retailers have been reluctant to create a specific market segment for IPM. Currently, in Europe, IPM products are rarely identified as such in the market place for end-consumers. However, retailers use IPM as a prerequisite for producers to deliver products to market segments with stricter environmental specification (Lamine et al. 2010). Complying with these general principles of IPM can lead producers to sell at higher prices (but not always) (Canali 2011). As a consequence of this market organization, market data on consumption of IPM products at household level are non-existent. As a result of the scarcity of market data for new or non-labelled products, the burgeoning literature on food choices relies increasingly on experimental data, using non-hypothetical and incentive compatible choice methods to elicit consumers' preferences and WTP (Becker, DeGroot and Marschak 1964). Several of these studies have focused on "green" or "eco" products, obtained from more sustainable farming systems, with the aim of distinguishing market segments and estimating their market potential at premium prices.

It has been previously shown that consumers are willing to pay more for reduced exposure to pesticide risk in general (Florax, Travisi and Nijkamp 2005) and for organic products in particular (Aertsens et al. 2009; Yiridoe, Bonti-Ankomah, and Martin 2002; Wier and Calverley 2002). However, it remains unclear how products complying with other environmental certifications are valued by consumers. While several studies have focused on estimating WTP for food products with environmental attributes other than organic, research on IPM is scarcer. Marette et al. (2012) studied the effect of a new label signalling for apples only using a few pesticides (corresponding to a $50 \%$ reduction in the pesticide use compared to conventional apples). The authors decided to name this alternative "Few Pesticides" rather than "Integrated Pest Management" in order to make the low-quantity of pesticides explicit to participants. Doing so, they have deliberately hidden part of IPM complexity, which is nonetheless an important feature to understand this market. Bazoche et al. (2013) elicited consumers' WTP for apples to which are attached different kinds of certification concerning pesticide use, including IPM. Here, the focus was placed on the impact of information provided to consumers concerning pesticide use, with control for sensory characteristics. Together, both studies suggest that IPM can satisfy a niche market for consumers with different preferences on the trade-off between price and pesticide reduction.

Our experimental study further contributes to the understanding of consumers' preferences for IPM, when conventional and organic products are also available, using the example of fresh tomatoes. Very few studies have focused on vegetables whereas vegetables have high market share within organic consumption and concentrate a lot of effort in IPM research (van der Velden et al. 2012). Although all the available evidence on preferences for tomatoes production systems to date focuses on organic (Weaver, Evans and Luloff 1992; Yue, Alfnes and Jensen 2009; Ali Bashir 2012; Mesías Díaz et al. 2012), this study complements the available literature by capturing in the laboratory the evolution of the legislative environment, according to which all growers in the EU should follow IPM guidelines (or be certified organic) from $1^{\text {st }}$ January 2014. Another contribution of this article is the focus on the analysis of the market impacts. While previous studies have provided estimations of WTP for IPM, we provide results on how the market shares may be redistributed across IPM and organic production when conventional 
products are withdrawn from the market. To do so, we investigated how IPM tomatoes consumption would be influenced by a reduced availability of conventional products and an increase in shelf space ${ }^{1}$ dedicated to IPM. Furthermore, the experimental design accounts for the potential impact of relative prices on consumers' preferences. Moreover, the impact of an innovative pricing mechanism that accounts for the potential impacts of demand on producers' willingness to adopt more sustainable farming practices was tested. We further capture, under laboratory conditions, the fact that, by increasing their demand of organic or IPM products, consumers can encourage their production, and in the medium term, prices of IPM and organic products may decrease when supply increases. We also analysed the impact of providing to consumers extra information on the characteristics of the final products (focusing on pesticide residue levels), in addition to the description of the production system.

Overall, the results allow for the provision of recommendations for effective marketing and pricing decisions of IPM products and for improving the consumer responses to the new legislative environment on IPM. The paper is structured as follows. Section 2 presents the method employed and data generated. Results are presented in section 3, and discussed in section 4. Section 5 provides conclusive remarks.

\section{Data and Method}

\subsection{Experimental Design}

The experiment focuses on the analysis of how preferences for IPM change according to three variables: products' availability, information and relative prices. First, we investigate how the purchase of IPM tomatoes is influenced by the availability of conventional and organic products, and by the shelf space dedicated to IPM. Second, the impact of providing extra information on the characteristics of the final products to consumers (focussing on pesticide residue levels), in addition to the usual description of the production system, was analysed. Lastly, the potential impact of relative prices on consumers' preferences was also assessed. The following sub-sections provide more information on the choice mechanism, the experimental procedure, the implementation of these different treatment variables, and finally on the characteristics of the participants.

\subsubsection{Choice mechanism}

While experimental auctions have been widely used to analyse consumers' preferences and WTP for new products, real/non-hypothetical choice experiments are developing quickly in agricultural economics to value private goods (Lusk and Schroeder 2004; Alfnes et al. 2006; Michaud, Llerena and Joly 2012; Ginon et al. 2014). While interpreting auction results is straightforward, explaining the auction mechanism to participants is not necessarily so (Corrigan et al. 2009). Experimental auctions are also criticized for their lack of realism, since food shoppers are usually not price makers. Real choice experiments are favoured for their ability to combine discrete choice questions with posted prices and real economic incentives. Such surveys typically require consumers to make choices between several alternatives defined

\footnotetext{
${ }^{1}$ The shelf space corresponds to the amount of space for one product in a store.
} 
by their attributes. Food shoppers are usually more familiar with such a decision task where there are price takers. In the overwhelming majority of retail transactions taking place in the field, consumers are presented with a fixed price at which they can buy one or more units of the good for sale. This is particularly true in the supermarket environment, where Europeans buy most of their food (Corrigan et al. 2009). The discrete choice experiment (DCE) methodology also has a sound theoretical basis given that they combine Lancaster's (1966) characteristics theory of value and McFadden's (1973) random utility theory. DCE also provides great flexibility in the sense that many different scenarios can be presented in a single study.

Most choice experiments analysing private goods consumption are based on choice cards and therefore offer participants to purchase at most one unit of one of the goods presented. A third valuation method that incorporates many of the advantages of both experimental auctions and DCEs is the non-hypothetical "open-ended choice experiment", used by Maynard et al. (2004) and Corrigan et al. (2009). As with more conventional choice experiments, participants in an open-ended choice experiment are presented with multiple goods for sale at different prices. And as with experimental auctions, participants provide open-ended responses. That is, they can choose to purchase as many units of the goods for sale as they wish. Unlike the name-yourreservation-price exercise in an experimental auction, the name-your-quantity exercise in an open-ended choice experiment is familiar to consumers who engage in a similar exercise every time they purchase food at a supermarket. The prices are fixed for each round, and participants choose one of the tomato options and the desired quantity. Choices are consequential, since one of the decisions was randomly drawn at the end of the experiment to be implemented for real.

Here, the choice of the open-ended choice experiment format was particularly relevant given that we needed the information on quantities to be able to compute market shares and evaluate the impact of a change in the treatment variables on market shares. For this reason, we also forced participants to buy a positive quantity (minimum $0.1 \mathrm{~kg}$ ). In other words, the experiment did not include an opt-out alternative. Opt-out alternatives have become fairly standard in discrete choice experiments and are generally recommended (Hensher 2010), specifically since opt-outs better reflect reality (Carson et al. 1994). Kallas et al. (2012) provide a comprehensive overview of the theory and implications of including an opt-out alternative, and Boxall, Adamowicz and Moon (2009) review potential bias from including an opt-out alternative. Yet recent studies without opt-out alternatives exist (Carlsson, Frykblom and Lagerkvist 2007; Hasund, Kataria and Lagerkvist 2011; Kallas et al. 2012; Rigby, Alcon and Burton 2010; Miettinen, Hietala-Koivu and Lehtonen 2004; Alphonce and Alfnes 2015) As we were primarily interested in estimating the impact of the different treatment variables on market shares, and not the total WTP for each product, this ought to be an appropriate design (Carlsson et al. 2007; Alphonce and Alfnes 2015).

\subsubsection{Experimental procedure}

At the beginning of the session, each participant received a cash endowment of 20 Euros. A session was composed of 10 rounds. As in open-ended choice experiment, in each round, each participant could choose the type and the quantity of tomatoes in Kilograms (s)he wanted to purchase, with a minimum of $0.1 \mathrm{~kg}$. It was possible to buy only one type of tomato in each round. As described in Table 1, prices varied across rounds (which is a common feature of 
open-ended choice experiment), but also product availability and information available to participants. All instructions are available in Appendix.

\section{[Insert Table 1 about here]}

To induce real economic incentives, it was made clear in the instructions that one of their decisions would be randomly drawn at the end of the experiment and implemented. As the random draw resulted in the purchase of the type and quantity of tomatoes they had chosen at the price specified, they had to consider each choice made during the experiment as a real purchase decision. The dominant strategy for participants was therefore to choose the alternative that they had a "real" preference for in each of the choice sets, thereby revealing their true preferences.

The experiment was performed individually and electronically implemented using z-Tree (Fischbacher 2007) in a standard individual choice manner. Participants could see the types of tomatoes available and their respective prices on the computer screen and had to enter the quantity and type of tomatoes they wished to buy. Efforts were undertaken to make the experiment similar to a real buying situation. Instead of pictures or images, real tomatoes were used as product stimuli. The five types of tomatoes were arranged on a table and participants were encouraged to view them during the experiment (see picture in the appendix). The number of tomatoes arranged on this table was modified during the experiment according to products' availability.

\subsubsection{Products and treatment variables}

\section{Products}

The choice set was composed of tomatoes from three production systems: IPM, conventional and organic tomatoes. We decided to include conventional and organic products in the choice set because IPM is often seen as a "third alternative" between these two types of production. We have included three types of conventional tomatoes in the first rounds: two vine varieties (Conv-VA, Conv-VB) and one round variety (Conv-R), to capture the fact that conventional tomatoes currently occupy most of the shelf space in supermarkets and that a diversity of varieties is proposed to the consumer.

We made sure the appearance of the tomatoes was similar across IPM, traditional and organic production methods. Only vine and round conventional tomatoes looked different.

The experiment was designed such that two conventional products for which the demand was the lowest in rounds 1 to 6 disappeared from round 7 (but the reason was not given to participants). On average over all rounds 1 to 6 , vine A were the most preferred conventional tomatoes, and were therefore the only conventional tomatoes available in rounds 7 and 8 . In rounds 7 and 8, all tomatoes available for sale had therefore a similar appearance.

\section{Prices}

To analyse the impact of prices on choices, the prices of the different tomatoes across sessions and in the different rounds were varied. Participants therefore indicated the quantity demanded at several price combinations, with the understanding that one of these will be randomly determined to be binding, as in Corrigan et al. (2009)'s open-ended choice experiment. In the first two rounds, the tomatoes were priced according to reference prices. Two lists of the 
reference prices (Table 2) were used according to those observed in retail contexts (supermarkets). The list "autumn" corresponded to the reference price observed the week before the experiment. The list "summer price" corresponded to the price of tomatoes in summer (cheaper than in autumn). All price lists were balanced among the experimental sessions. Participants of sessions 1, 2, 3, 6, 7 and 8 received the "autumn prices" and participants of the other sessions received "summer prices". In addition to this between-session treatment variable, three different price lists were tested in the different rounds (within-subject treatment variable). The difference between the prices of organic and IPM tomatoes was increased compared to reference prices in price list 2 and was reduced in price list 3 . The full list of prices is available in Table 2 and the price list associated to each round is specified in Table 1. Given the complexity of the experimental design, and the focus on its realism, we cannot claim to perfectly capture the impact of prices on consumption.

\section{[Insert Table 2 about here]}

Moreover, the impact of an innovative pricing mechanism that accounts for the potential impacts of demand on producers' willingness to adopt more sustainable farming practices was tested. In reality, by increasing their demand of organic or IPM products, consumers can encourage their production, and in the medium run, prices of IPM and organic products may decrease when supply increases. We tried to capture this effect in the lab and refer to this mechanism as the "price endogeneity mechanism". In half of the sessions (sessions 6 to 10), the participants received the following information at the beginning: "If many of you choose to buy organic or IPM tomatoes, the prices of these tomatoes will decrease for the participants of the other sessions". ${ }^{2}$ More precisely, the experiment was configured as follows: if the market share of IPM was higher or equal to $70 \%$ in round $t$ and session $X$, the price of IPM was reduced by $20 \%$ in round $t$ of the next sessions, as compared to the prices in Table 2 (and the same applies for organic). For the sessions 1 to 5 conducted in absence of the price endogeneity mechanism, prices were those indicated in Table 2.

\section{Information on the production system and extra information on residues}

Given the difficulty to present IPM guidelines to the end-consumer, we intended to test whether providing extra information on the characteristics of the final products (focusing on pesticide residue levels), in addition to information on the production system and crop protection strategies, were useful to promote IPM. In the experiment, participants were able first to access the information on the technical specifications of the production system of each type of tomatoes, by clicking on a dedicated button if they wanted. Then, starting from round 5 on, they could access extra information on the properties of the final product in terms of residue levels.

2 The design can be interpreted as a modified voluntary contribution mechanism. In the traditional voluntary contribution mechanism, each member of a group of potential beneficiaries of the public good decides simultaneously on a portion of its initial endowment to contribute to a group account. Here, the contributions to the public good do not benefit directly to the group but are transferred over time to a future group (intertemporal transfers). Moreover, we combine the voluntary contribution mechanism with supply and demand conditions in the market for a private good. Here, the "public good", provided thanks to individual contributions, is a reduction in the price of sustainable products for next generations. 
Successively revealing information to participants with regard to various characteristics of the product under study is a common design feature of food choices experiments (Marette et al. 2012). Most of the time, information is displayed to all participants and data are analysed assuming that all the information provided is processed to make informed decisions. Here, in contrast, participants had to click to view the information. Voluntary access to information better captures a real shop situation where consumers have to actively look for information (either on the label or on the internet) (Hu et al. 2006). Here, extra information was introduced sufficiently early in the experiment to account for the potential diminished attention to new information at the end of the experiment. The experiment focuses on the impact of providing extra information, not on the identification of the separate effect of the two types of information. We therefore did not rely on a between-subject design where some participants would have access to information on the production system while others have the information on residue levels, nor tested order effects.

Starting from round 7 on, the complete information was disclosed to all participants as to ensure the possibility of measurement of the net impact of the other treatment variables (reduction in the shelf space dedicated to IPM and relative prices), assuming all consumers are informed. The content of this information is presented in the instructions (see Appendix).

\section{Shelf space dedicated to IPM}

In order to capture the evolution of the legislation on crops pest management, the shelf space dedicated to conventional tomatoes during the experiment was gradually reduced. At the beginning, participants were able to purchase fresh tomatoes from the conventional production system of three varieties, one type of IPM tomato and one type of organic (round 1 to 6). This captures the current situation where conventional farming remains the norm and conventional tomatoes occupy a large shelf space (3/5). Then, we reduced the number of different conventional tomatoes available for sale from 3 to 1 (round 7 to 10). The shelf space of IPM and organic tomatoes therefore mechanically increased (from 1/5 to $1 / 3$ ). In the last rounds (rounds 9 and 10), conventional tomatoes were not available anymore and organic and IPM tomatoes equally shared the shelf space.

To summarize, the number of products in the choice set varies across rounds: 5,3 or 2 . There are three types of production systems, but with three types of conventional tomatoes in the first rounds, therefore a total of five types of tomatoes.

Participants were provided with explanations on the justification for the changes in the products available (messages in Table 1).

We investigate the impact of the shelf space only in a context of full information (complete information was disclosed to all from round 7). Here, the design choice is driven by a concern for realism in a retail environment, since, in real markets, when conventional products will disappear from the shelves, we assume consumers will be aware of the characteristics of the alternatives (organic and IPM).

Moreover, in each session, the order of presentation of the different types of tomatoes was modified on the computer screen to help avoid position bias. Five different orders were tested over the ten sessions. 


\subsubsection{Participants}

The experiment was conducted at the Laboratory for Experimentation in Social Sciences and Behavioral Analysis (LESSAC) in Dijon, France, in November 2013. Participants were recruited using two different procedures: half of the participants were randomly selected from a panel of volunteer consumers having participated in other studies at LESSAC and half were recruited thanks to posters in the market of Dijon city and by word of mouth.

The experiment was conducted in November, therefore we recruited participants who usually buy tomatoes in autumn/winter in order to ensure they will be interested in buying tomatoes during the experiment. ${ }^{3}$ We believe this specific selection reinforces the implication of our participants in the task, but might introduce a selection bias. Indeed, we can expect that the sample excludes some of the frequent consumers of organic products, usually buying seasonal vegetables. In addition, as in all standard survey sample selection procedure, there may also be some other sources of sample selection bias (self-selection, concerns with food habits...). Given these potential sources of biases, our findings may not fully represent habits of the general population, which is a classical limitation of experiments. However, these limitations are outweighed by the precise control of revealed information to participants, which is a real added value of lab experiments.

189 food shoppers (129 female and 60 male), aged between 22 and 75, participated at this experiment. Participants were asked to fill out a detailed questionnaire on their sociodemographic and consumption characteristics at the end of the experiment. The sample is relatively balanced in terms of age and consumption habits (Table 3). The high percentage of female respondents was expected and desirable, since we were targeting actual shoppers and French female tend to be usually in charge of the task.

\section{[Insert Table 3 about here]}

A total of ten sessions, of less than 90 minutes each, were organised. Participants were randomly assigned to each session, a priori ensuring that the socio-demographic characteristics of the participants were not significantly different across the different sessions. Each participant was involved in only one session.

\subsection{Method for data analysis}

In order to measure the impact of the different treatment variables on consumption choices, two approaches were relied upon. First, we focused on market level, and measured the impact of the different variables of the experimental design on market shares. Second, we focused on individual preferences for the different types of tomatoes.

\subsubsection{Market shares}

From retailers' point of view, the quantities bought by the consumers are an important piece of information to understand the evolution of the market in the presence of new products. To account for quantities, we compared the market shares of each type of tomato across rounds

\footnotetext{
3 In the recruitment email, respondents were asked which vegetables they were used to buy at this period of the year (autumn) in a list of ten vegetables.
} 
and sessions. The market share of product $j$ in round $t$ is defined as the total quantities of product $j$ purchased in round $t$ by all participants divided by the total quantities of tomatoes bought in round $t$ (all types of tomatoes). To measure whether the differences across rounds are significant, we relied on non-parametric tests, comparing the quantities purchased by each participant of the different types of tomatoes. More specifically, we use the Wilcoxon MannWhitney two-sample test to compare the choices of participants in different sessions (between subject treatment variables) and the Wilcoxon matched-pairs signed-ranks test for comparing choices across rounds (within subject treatment variables). Lastly, we verified whether the distributions of the quantities purchased over the different rounds are different. To do so, we relied on the Skillings-Mack statistic, which is useful for the data obtained from block designs with missing observations (Chatfield and Mander 2009). Here there are missing data when the product was not available in some rounds.

\subsubsection{Discrete choice model}

The theoretical framework for analysing the choice of tomatoes is a random utility model. Formally, consider a consumer $i$ from a sample of $N$ consumers who has to choose a type of tomatoes defined by $j=1,2,3$ alternatives, namely, IPM $(\mathrm{j}=1)$, conventional $(\mathrm{j}=2)$, and organic $(\mathrm{j}=3)$. Each consumer $i$ attaches a utility value $U_{i j}$ to each type of tomatoes and chooses the type of tomatoes $j$ that maximizes her utility in each choice situation.

Following the approach of Alvarez et al. (2000) and Jumbe and Angelsen (2011), we use a multinomial probit model (MNP). The MNP does not impose the independence of irrelevant alternatives (IIA) property inherent in other multinomial choice models such as the multinomial logit because the error process of the MNP allows for correlations between the disturbances for the different choices (Train 2009). The choice of the MNP has been motivated by the desire to relax IAA and to allow for more flexible substitution patterns between alternatives. This is particularly relevant here given that we wanted to analyse substitutability across different types of tomatoes, when the choice set is modified by a change in the legislative environment. ${ }^{4}$ The MNP is also flexible in that not all cases need to have faced all $\mathrm{J}$ alternatives. This is a useful feature given that the choice set varies from 3 (conventional, IPM and organic) in rounds 1 to 8 , to 2 (IPM and organic) in rounds 9 and 10. Moreover, errors were clustered at the individual level in order to take into account that the same individual is making 10 choices (one per round). The model does not account for the quantities purchased by each individual since we observed that the quantity bought by each individual is stable across rounds (see section3.1).

The utility that a consumer obtains from alternative $j$ is decomposed into observed and unobserved parts:

$$
U_{i j}=X_{i j} \beta+z_{i} \alpha_{j}+\varepsilon_{i j} \forall j=1,2,3
$$
logit also has the advantage not to require an identical and independent distribution of error terms across individuals and alternatives. It allows estimating standard deviations of mean parameters and therefore heterogeneity in the preferences for a particular attribute. The MNP is nevertheless preferred because the estimation is less time-consuming than the mixed logit. Moreover, the MNP assumes the errors are distributed multivariate normal. Assuming normality may be more convenient or not worse than choosing a specific distribution as required in the mixed logit (Train 2009). 
With $\mathrm{V}_{i j}=X_{i j} \beta+z_{i} \alpha_{j}$ the deterministic part of the model, where $\mathrm{X}_{i j}$ is a vector of alternativespecific variables (price, shelf space dedicated to the alternative, information of the respondents on this alternative $\left.{ }^{5}\right), \beta$ is a vector of parameters, $z_{i}$ is a vector of individual-specific variables including socio-economic characteristics of the respondent (sex, age, weekly consumption of tomatoes in autumn, usual price paid for tomatoes, share of organic in tomatoes consumption) and descriptors of the decision context (autumn prices, order of presentation of the products, price endogeneity mechanism), $\alpha_{j}$ is a vector of parameters of the $j$ th alternative and $\varepsilon_{i j}$ the error term.

The choice probability of alternative $j$ rather than any other alternative $j^{\prime}$ for individual $i$ is given by:

$$
\begin{aligned}
P_{\mathrm{ij}} & =\operatorname{Prob}\left(\mathrm{V}_{\mathrm{ij}}+\varepsilon_{i j}>\mathrm{V}_{\mathrm{ij} j^{\prime}}+\varepsilon_{i j^{\prime}}\right) \quad \forall \mathrm{j} \text { and } \mathrm{j}^{\prime} \neq \mathrm{j} \\
& =\operatorname{Prob}\left(\varepsilon_{i j^{\prime}}-\varepsilon_{i j}<\mathrm{V}_{\mathrm{ij}}-\mathrm{V}_{\mathrm{ij}}\right) \\
& =\int_{\varepsilon} I\left(\varepsilon_{i j}-\varepsilon_{i j}<\mathrm{V}_{\mathrm{ij}}-\mathrm{V}_{\mathrm{ij}}\right) f\left(\varepsilon_{i}\right) d \varepsilon_{i} \quad \text { (2) }
\end{aligned}
$$

Where $I($.$) is the indicator function, equalling 1$ when the expression in parenthesis is true and 0 otherwise. This is a multidimensional integral over the density of the unobserved portion of utility $f\left(\varepsilon_{i}\right)$. In the MNP, $f(\quad)$ is multivariate normal with zero means and the variancecovariance matrix $\Omega$.

$$
\Omega=\left(\begin{array}{ccc}
\sigma_{i, 1}^{2} & \sigma_{i, 12} & \sigma_{i, 13} \\
\sigma_{i, 12} & \sigma_{i, 2}^{2} & \sigma_{i, 23} \\
\sigma_{i, 13} & \sigma_{i, 12} & \sigma_{i, 3}^{2}
\end{array}\right)
$$

In general, a model with $\mathrm{J}$ alternatives has $\mathrm{J}(\mathrm{J}+1) / 2$ distinct elements in the covariance matrix of the errors (here 6 elements). As described by Train (2009), the model requires normalization because both the level and scale of utility are irrelevant. To take account of the fact that the level of utility is irrelevant, we take utility differences with respect to the first alternative $(j=1$, IPM tomatoes). We selected IPM as the base alternative since IPM is bound to become the main production system in the new legislative environment and our interest is on the substitution between IPM and conventional, and IPM and organic products.

The covariance matrix for the vector of error differences takes the form:

$$
\widetilde{\Omega}=\left(\begin{array}{ll}
\theta_{22} & \theta_{23} \\
\theta_{23} & \theta_{33}
\end{array}\right)
$$

\footnotetext{
$5 \quad$ While price and shelf space are attributes of the alternatives defined in the experimental design, the value of the information attributes are not fixed prior to the experiment since they depend on whether the individuals have requested information about a specific alternative (for rounds 1 to 5) or not. Nevertheless, they remain alternative-specific attributes.
} 
where the $\theta$ 's relate to the original $\sigma$ 's of equation (3) as follows:

$$
\begin{aligned}
& \theta_{22}=\sigma_{22}+\sigma_{11}-2 \sigma_{12}, \\
& \theta_{33}=\sigma_{33}+\sigma_{11}-2 \sigma_{13}, \\
& \theta_{33}=\sigma_{23}+\sigma_{11}-\sigma_{12}-\sigma_{13},
\end{aligned}
$$

To set the scale of utility, one of the diagonal elements of $\widetilde{\Omega}$ is normalized. We set the top-left element to 1 . This normalization for scale gives us the following covariance matrix:

$$
\widetilde{\Omega}^{*}=\left(\begin{array}{cc}
1 & \theta^{*}{ }_{23} \\
\theta^{*}{ }_{23} & \theta^{*}{ }_{33}
\end{array}\right)
$$

The $\theta^{*}$ 's relate to the original $\sigma$ 's as follows:

$$
\begin{gathered}
\theta^{*}{ }_{33}=\frac{\sigma_{33}+\sigma_{11}-2 \sigma_{13}}{\sigma_{22}+\sigma_{11}-2 \sigma_{12}} \\
\theta^{*}{ }_{23}=\frac{\sigma_{23}+\sigma_{11}-\sigma_{12}-\sigma_{13}}{\sigma_{22}+\sigma_{11}-2 \sigma_{12}}
\end{gathered}
$$

The model with $\mathrm{J}=3$ alternatives now has two $(\mathrm{J}(\mathrm{J}-1) / 2-1)$ covariance parameters after normalization. The reduction in the number of parameters is a normalization that simply eliminates irrelevant aspects of the original covariance matrix, namely the scale and level of utility, which have no relevance on behaviour. Estimation of the multinomial probit involves estimating $\widetilde{\Omega}^{*}, \beta$ and $\alpha_{j}$.

The MNP model imposes a significant computation burden because of the need to evaluate probabilities from the multivariate normal distribution. These probabilities are evaluated using simulation techniques because the integral in equation (2) cannot be solved analytically. The model was estimated using maximum simulated likelihood, implemented by the GewekeHajivassiliou-Keane (GHK) algorithm (asmprobit in Stata 14).

\section{Results}

\subsection{Descriptive analysis of market shares}

Participants bought on average $0.70 \mathrm{~kg}$ of tomatoes in each round. This quantity corresponds to the average weekly consumption of tomatoes in autumn/winter declared by the participants in the post experiment questionnaire. Moreover, only between 10 and 13 participants per round have chosen the minimum quantity $(0.1 \mathrm{~kg})$. These two elements confirm participants' overall interest in buying tomatoes during the period of our study and the fact that the experiment is perceived as a real purchase opportunity.

Participants have purchased different types of tomatoes in the different rounds, suggesting that they have different preferences for the different attributes of the products. The Skillings Mack 
statistics shows that the differences in the quantity purchased of each type of tomatoes were statistically significant across rounds (IPM: Skillings-Mack statistic $=114.293$, p-value $=0.000$; Organic: Skillings-Mack statistic $=137.048$, p-value $=0.000$; Conventional: Skillings-Mack statistic $=218.033$, p-value $=0.000)$. Only 13 participants $(6.88 \%)$ made the same choice of tomato type during the ten rounds. Among them, ten always chose organic tomatoes. These ten consumers declared to consume on average $72.5 \%$ of organic in their real-life tomato consumption. They exhibited strong preferences towards organic in the experiment as in real life, and they seemed to be less influenced by the changes in the treatment variables across rounds.

However, we cannot reject the hypothesis that the quantity of tomatoes purchased (all types) is equal across rounds (Skillings-Mack statistic=7.222, p-value=0.6140), suggesting that participants did not modify the quantities purchased when they switched to another type of tomatoes (even if the price was higher or lower). This suggests that participants to the experiment are willing to purchase a fixed amount of tomatoes in the experiment, certainly according to their needs for the week. They seem to have understood that it is rational not to vary this quantity in the different rounds given that only one round was randomly drawn for real purchase.

\section{Impact of the between-subject design variables}

We observed a mostly non-significant impact of the between-subject variables. First, the quantities of conventional, IPM and organic tomatoes bought in the round 1 were not significantly different across sessions with different orders of presentation of the products.

Moreover, the market share of IPM tomatoes averaged over all rounds was equal with summer and autumn prices (33\%). However, given that the price premium for organic tomatoes is lower in summer, the market share of organic tomatoes was higher in sessions with summer prices (39\% versus $33 \%$ in autumn), at the expense of conventional tomatoes (28\% versus $35 \%$ in autumn).

Last, the price endogeneity mechanism had an impact, but only in the first round. In round 1, in the sessions with the mechanism, participants purchased significantly less conventional tomatoes and significantly more IPM tomatoes (significant at the $1 \%$ level), while the quantities of organic tomatoes purchased are the same with and without the mechanism. But in the other rounds, no significant differences were observed between the quantities of conventional, IPM and organic tomatoes bought by the participants of the sessions with and without the mechanism. Moreover, the $70 \%$ threshold for the market share of organic or IPM tomatoes necessary to trigger the price endogeneity mechanism was never reached in any of the rounds or sessions. This suggests that informing participants that their choices will impact future prices had a low impact in this experiment, at least not sufficient to reduce future prices.

Given these results of mostly non-significant impact of the between-subject variables, data of all sessions were pooled (with the different order of presentation of the products, with autumn and summer prices, and with and without price endogeneity mechanism). We systematically verified that similar conclusions were reached when analysing the data separately in the different sessions. 
Market shares in the different rounds for all ten sessions are presented in Figure 1. The quantities purchased by each participant of each type of tomatoes were compared between two rounds with the non-parametric tests specified in section I.2.1. The results of these tests are presented in Table 4. They illustrate the impact of the different within-subject treatment variables.

\section{[Insert Figure 1 about here] \\ [Insert Table 4 about here]}

We now detail the result for each treatment variable in the experimental design, based on Figure 1 and Table 4.

Impact of relative prices (comparison between rounds 2 and 3,3 and 4, 5 and 6, 7 and 8 , 9 and 10)

The market share for conventional tomatoes increased between rounds 2 and 3 (from 29 to $55 \%$ ), when IPM and organic tomatoes became relatively more expensive compared to conventional tomatoes. This substitution impacts more the organic market (30\% in round 2 to $15 \%$ in round 3 ) than the IPM market ( $41 \%$ to $31 \%$ ). This is explained by the fact that there is a larger price difference between IPM and organic tomatoes in round 3 than round 2. Between rounds 3 and 4, organic tomatoes win market shares at the expense of IPM tomatoes (with the market share of conventional tomatoes remaining stable). IPM market share drops from $31 \%$ to $14 \%$ and the quantities of IPM tomatoes purchased are significantly lower, due to the smaller price difference between organic and IPM tomatoes in round 4 than in round 3 . The same result is observed in rounds 5 and 6, 7 and 8 and 9 and 10. All these differences are significant according to the non-parametric tests on the quantities purchased (Table 4).

Impact of the shelf space dedicated to IPM (comparison between rounds 5 and 7, 6 and 8, 7 and 9, 8 and 10)

The reduction in the shelf space dedicated to conventional tomatoes after round 6 had a significant impact on the quantities of IPM and organic tomatoes bought. More precisely, in terms of market shares, it benefited equally organic and IPM tomatoes. The market share of organic rose from $21 \%$ in round 5 to $33 \%$ in round 7 and from $37 \%$ in round 6 to $55 \%$ in round 8 , and for IPM it rose from $30 \%$ in round 5 to $47 \%$ in round 7 and from $21 \%$ in round 6 to $29 \%$ in round 8 . When conventional tomatoes totally disappeared from the market after round 8 , it benefited more IPM than organic when the price difference between organic and IPM was large (round 9). The market share rose from $47 \%$ in round 7 to $61 \%$ in round 9 for IPM and from $33 \%$ in round 7 to $39 \%$ in round 9 for organic. However, when the price premium for organic is low (round 10), even if organic tomatoes are more expensive than IPM tomatoes, the withdrawal of conventional tomatoes benefited mostly the organic market (from 55\% in round 8 to $72 \%$ in round 10), and no significant change in IPM consumption was observed between rounds 8 and 10 .

\section{Impact of information (comparison between rounds 1 and 2, 3 and 5, 4 and 6)}

First, we verify that most participants exhibited interest in getting more information about the products. In the last round before full disclosure of the information to all participants (round 6), 
only $23 \%$ of the participants did not read any information on conventional production systems, $17 \%$ on IPM and $33 \%$ on organic farming (Figure 2). This suggests that participants were curious and willing to learn about unknown production systems such as IPM. Participants were clearly less interested in information on organic farming, which was expected given the high perceived knowledge of organic agriculture in the French general public. Among the participants looking for information, most of them have showed interest in both level of information (on the production system and the characteristics of the final product in terms of residues). Only a small percentage of participants only looked at the information on the residues without reading the information on production.

\section{[Insert Figure 2 about here]}

Second, we analyse the impact of information disclosure on market shares on the basis of Figure 1 and Table 4. In round 1, in the absence of any information on the different tomatoes, the market share of conventional tomatoes was the highest $(61 \%)$ and corresponding to the shelf space dedicated to them (3/5). Moreover, even if organic tomatoes were the most expensive, the market share of organic tomatoes was slightly higher than that of IPM tomato. A strong and positive impact of the information on the production system disclosed in round 2 was observed. Indeed, in round 2, the market share of IPM was increased compared to round 1, at the expense of conventional tomatoes (the market share of organic products is not significantly impacted).

When extra information on the characteristics of IPM product in terms of residues was available from round 5, the quantities of IPM tomatoes bought significantly increased in round 5 compared to round 3 and round 6 compared to round 4. It suggests that the extra information on the residues levels also had an impact in convincing new consumers to switch to IPM (accounting for the fact that some of the consumers had already switched as a result of the information on the production system). To further comment on the impact of information on consumption choices, we would need to distinguish the consumption patterns of the participants who chose to access information from those who did not look at the information on each of the three types of tomatoes. To do so, we rely on the results of the multinomial probit model presented in the next section.

In order to better understand how these different factors interact to impact consumers' decisions, we analysed individual choices between the different tomatoes with an econometric model. The multinomial probit model allows to take into account the dependence of choices of an individual, as well as the dependence of choice between alternatives. The estimates allow to provide a measure of the identified impacts of the variables of interest. The multinomial probit model does not allow to account for the quantities chosen, which is acceptable given that the quantity of tomatoes purchased (all types) is equal across rounds.

\subsection{Econometric analysis}

We present the estimates from the multinomial probit model of the determinants of consumer choice of tomatoes in Table 6 and the marginal effects in Table 7. Table 5 summarizes the explanatory variables. All interpretations are based on the estimated marginal effects.

[Insert Table 5 about here]

[Insert Table 6 about here] 
We first tested whether IIA is violated. Under the IIA assumption, we would expect no systematic change in the coefficients if we excluded one of the alternatives from the model. We re-estimated the parameters, excluding the conventional alternative, and performed a Hausman test against the fully efficient full model. We reject the null hypothesis of no systematic differences in coefficients (chi $2=152.27$; Prob $>$ chi $2=0.00$ ). Furthermore, a test of multicollinearity amongst the independent variables was conducted. The findings of the test show that there is multicollinearity amongst the autumn and order dummy variables. As a result, we did not include the autumn dummy in the model, since we had highlighted in the previous section that the between-subject treatment variable summer versus autumn prices had no significant impact on market shares of IPM.

Results from non-parametric tests on the non-significant impact of the price endogeneity mechanism and order between-subject design variables are confirmed in the multinomial probit, suggesting that preferences are not impacted by the price endogeneity mechanism and the order of presentation of products in the first rounds.

Female consumers are 9\% more likely to consume IPM tomatoes, but gender differences are not significant for conventional and organic consumption. Age has a significant negative influence on IPM and positive influence on organic consumption, but the per-year effect is small. The usual price paid for tomatoes has no significant influence on any of the choices. Frequent consumption of organic products has, however, an impact on choices in the experiment: it significantly increases the probability to choose organic and reduces the probability to choose conventional and IPM (but to a lower extent) tomatoes. This confirms that laboratory tests are not so disconnected from a real purchase situation. The lower impact on IPM choice seems to suggest that both organic consumers and non-organic consumers are interested in IPM in the experiment.

The price, shelf space and information coefficients are almost all significant, which confirms that the tested treatment variables influenced consumers' choices. As expected, the price has a negative influence and the shelf space dedicated to a product has a positive influence on the probability to select an alternative.

Concerning the impact of prices, increasing the price of conventional tomatoes by 10 Euro cents per kilogram decreases conventional tomato consumption choice by 1.9 percentage points, and correspondingly increases by 1.1 and 0.8 percentage points the consumption of IPM and organic tomatoes respectively. Interestingly, reducing the price of IPM by 10 Euro cents significantly increased consumption of IPM (5.3 percentage points), mostly at the expense of organic consumption which decreased by 4.2 percentage points, while conventional tomatoes consumption decreased only by 1.1 percentage point. Symmetrically, increasing the price of organic tomatoes by 10 Euro cents benefits mostly to IPM ( +4.1 percentage points). Those results hold only under the assumption of similar price effect between the different treatments. Our model does not allow to test whether the effect of price varies with the level of information and the shelf space. 
A similar pattern is observed for the impact of shelf space dedicated to each type of tomatoes. Our results indicated that increasing shelf space dedicated to IPM by 10 percent would lead to a 21.4 percentage point increase in IPM consumption, and significantly reduce conventional tomatoes consumption by 4.5 , and organic by 16.9 percentage points, respectively. Similarly, a 10 percent reduction in the shelf space for conventional tomatoes reduced conventional consumption by 7.9 percentage points, whilst significantly increasing IPM and organic consumption by 4.5 percentage points and 3.4 percentage points, respectively.

We also observed a significant positive impact of information on consumption. Consumers informed on a production system (variable "infol") are significantly more likely to buy the tomatoes corresponding to this production system and less likely to consume other tomatoes. Overall, information had a larger impact for IPM and organic than conventional tomatoes. One could have expected a negative impact of being informed on conventional production on the probability to choose conventional tomatoes, but we did not observe such an effect. The impact of the extra information on the final characteristics of the product, in terms of residue levels (variable "info2"), was lower and significant only at the $10 \%$ level for IPM. Everything else equal, being informed on IPM production system increased the probability to choose IPM tomatoes by 11 percentage points, but mostly at the expense of organic tomatoes since conventional consumption reduces less than organic consumption (respectively 2.3 and 8.7 percentage points). Symmetrically, being informed on organic increased the probability to choose organic tomatoes, but mostly at the expense of IPM tomatoes. 


\section{Discussion}

Results from the multinomial probit allow the identification and comparison of three levers to foster IPM consumption. First, according to these experimental results, increasing by $10 \%$ the shelf space dedicated to IPM can increase IPM consumption by 21.4 percentage points. Second, increasing the share of consumers informed on IPM production guidelines can increase consumption by 19.4 percentage points. Last but not least, reducing the price of IPM can foster consumption ( +5.2 percentage points for 10 Euro cents reduction). In the absence of any information on the cost of implementing such actions, it is not possible to compare what is the most cost-efficient lever. Nevertheless, our experimental results suggest that they are all likely to modify consumption patterns.

We observed that consumers' preferences for IPM tomatoes are strongly impacted by the price difference with organic counterparts. The market share of IPM drops when the price difference between IPM and organic is reduced. Moreover, when conventional tomatoes are withdrawn from shelves, we observe that IPM wins market shares only if the price difference with organic tomatoes is sufficiently high (at least 60 cents per $\mathrm{kg}$ ). Results of the multinomial probit also suggest that if prices of conventional tomatoes increase (for example due to a tax on chemical input use), conventional tomatoes consumption will decrease, but it will benefit slightly more to organic than IPM consumption. Only a significant reduction in the price of IPM tomatoes compared to organic ones can foster IPM consumption. Moreover, we observed that increasing the shelf space dedicated to IPM leads to an increase in IPM consumption, mostly at the expense of organic tomatoes. The substitutability of IPM and organic tomatoes was also visible through the impact of information since being informed on IPM increased the probability to choose IPM tomatoes, mostly at the expense of organic tomatoes, and vice-versa.

Taken together, the above results indicate that strong substitution opportunities exist between IPM and organic tomatoes, while substitution with conventional tomatoes is more limited. This somehow contrasts with result of previous research which showed that IPM was perceived by consumers as a third way, but closer to conventional than organic. Marette et al. (2012) found that the average WTP for apples with a "few pesticides" label was closer to the WTP for conventional apples than the WTP for organic apples. Bazoche et al. (2013) found that, compared with the regular product, the average premium for IPM certification is 24.5 per cent, while it is equal to 50.5 per cent for organic certification.

Given the low knowledge and recognition of IPM in the French general public, understanding how to communicate about IPM to the end-consumers appears to be a crucial element to make sure IPM will be seen as profitable by producers. We observed in our experiment that consumers are more interested in information on IPM than on conventional and organic farming. They show interest in the information on the production system and the characteristics of the final product. We have found that consumers increase their consumption of IPM products when they get access to information on this production system. This suggests that retailers could start communicating to the end-consumer on IPM, rather than limiting IPM as a market-access tool.

However, while residues control is a rapidly growing component of private standards and supermarket communication to consumers, we observed that providing extra information on 
the residue levels to consumers, in addition to the information on the production system, has a limited influence on consumers' choices. This suggests that for those consumers not reacting to the information on the production systems, extra information on residue levels may modify their purchase habits, but the overall effect will be small. It confirms that only some individuals are responsive to information campaigns and changing the content of the information does not allow reaching other population segments. A further interpretation could be that consumers are not yet ready for messages highlighting the complex and uncertain links between actions (pesticide use) and results (pesticide residues in food). We know from the scientific literature that some of the applied pesticides find their way as residue in food, but their residual quantity differs according to the type of pesticides, the type of products and the production system (Bakery et al. 2002). In the coming years, it will be interesting to confront these results with the analysis of retailers marketing and communication strategies on IPM, in particular with reaction to the new EU legislation.

Concerning the non-significant impact of informing consumers that their consumption choices today impact future prices of IPM and organic tomatoes, this would suggest that the option to educate consumers on the impact of their consumption choices on future prices is not efficient (if the results could be generalized). One explanation could be that participants' incentives to contribute to price reduction are reduced in an intertemporal setting like the one of this experiment (where the price reduction does not benefit to the individuals themselves, but only to the participants of future sessions). We know that intertemporal settings create anonymity of contributions, and previous research has shown that anonymity reduces social or altruistic preferences and voluntary contributions to a public good (Andreoni and Petrie 2004; Rege and Telle 2004; Alpizar, Carlsson and Johansson-Stenman 2008). Moreover, while other researchers have found that the intertemporal setting can favour the idealistic/non-purely economic motives, and therefore the contribution to the public good (Grolleau, Sutan and Vranceanu 2013) such drivers may be difficult to activate here given that the benefits are a reduction in prices, i.e. something associated with economic motives. Furthermore, one cannot guarantee that the price endogeneity mechanism would have a different effect with another threshold value or another way to present the information. Such a test is outside the scope of this experiment but could be of interest for future research. 


\section{Conclusion}

This paper analysed consumers' choices between IPM, conventional and organic tomatoes. We have conducted an open-ended choice experiment with 189 French consumers, selected from a sample of ordinary food shoppers. In each of the ten rounds of the experiment, participants could choose to buy fresh tomatoes, indicating the type of tomatoes (conventional, IPM or organic) and quantity they wanted. The experiment was designed to analyse how IPM purchase would be influenced by a reduced availability of conventional products and an increase in the shelf space dedicated to IPM products following the change in the European legislation on crop protection. Furthermore, we also studied the impact of providing extra-information to the consumers on the pesticide residues in tomatoes, in addition to the information on the different production systems and crop protection strategies.

These experimental results indicate the existence of strong substitution opportunities between IPM and organic tomatoes, whilst substitution with conventional tomatoes appears more limited. Experimental results also indicate that the withdrawal of conventional tomatoes from shelves due to the implementation of the SUD could benefit organic rather than IPM sales if the price difference between organic and IPM is low, even if organic products are more expensive. Only a significant reduction in the price of IPM tomatoes, compared to organic and/or an important increase in the shelf space dedicated to IPM, would appear to increase IPM sales. However, raising awareness on the impact of consumption choices on future prices of the product has only a limited impact in this context. Results also provided an insight into the nature and extent of information for communication to consumers to increase their understanding of IPM. While information on IPM guidelines increases IPM products purchases, providing extra information on residue levels in IPM tomatoes has no further impact on consumers' choices. Of course, these results are valid only in the context of this particular experiment. Given potential biases due to the method used for participant's selection and the fact that the experiment was conducted in November (with participants who usually buy tomatoes in autumn/winter) care should be taken in the generalization of results.

Given the importance of the relative prices to trigger a change in consumption pattern in favour of IPM products, our results call for further research in two directions: first, on the "price endogeneity mechanism", and second, on the impact of IPM adoption on production costs.

Concerning the first line of research, our results are limited given that we did not test different threshold values to trigger a reduction in prices when consumption increases. Such a test was outside the scope of this experiment but could be of interest for future research.

Concerning the second line of research, overall, there is a lack of quantitative evidence on the potential of IPM to increase economic sustainability relative to non-IPM strategies under region- and crop-specific growing conditions. Indeed, data on the economic costs of IPM solutions are scarce, and even more so with consideration of the European context (Lefebvre et al. 2015). None of the existing studies (Vasileiadis et al. 2011; Pelzer et al. 2012; Mouron et al. 2012) focuses on tomatoes production. More information on IPM production costs in the long run will further help to guide producers' and retailers' pricing decisions in the new context. 


\section{References}

Aertsens, J., W. Verbeke, K. Mondelaers, and G. Van Huylenbroeck. (2009) Personal determinants of organic food consumption: a review. British Food Journal 111(10):1140-1167.

Alfnes, F., A.G. Guttormsen, G. Steine, and K. Kolstad. (2006) Consumers' willingness to pay for the color of salmon: a choice experiment with real economic incentives. American Journal of Agricultural Economics 88(4):1050-1061.

Ali Bashir, K (2012) Determinants of willingness-to-pay a premium for organically produced tomatoes in Riyadh City, Kingdom of Saudi Arabia (KSA). African Journal of Agricultural Research 7(43):5726-5733.

Alphonce, R., and F. Alfnes. (2015). Eliciting Consumer WTP for Food Characteristics in a Developing Context: Comparison of Four Valuation Methods in a African Market.’Journal of Agricultural Economics, doi: 10.1111/1477-9552.12170

Alpizar, F., F. Carlsson, and O. Johansson-Stenman. (2008). Anonymity, reciprocity, and conformity: Evidence from voluntary contributions to a national park in Costa Rica. Journal of Public Economics 92(5-6):1047-1060.

Alvarez, R.M., J. Nagler, and S. Bowler. (2000). Issues, Economics, and the Dynamics of Multiparty Elections: The British 1987 General Election. The American Political Science Review 94(1):131.

Andreoni, J., and R. Petrie. (2004). Public goods experiments without confidentiality: a glimpse into fundraising. Journal of Public Economics 88(7-8):1605-1623.

Aubertot, J.N., J.M. Barbier, A. Carpentier, J.J. Gril, L. Guichard, P. Lucas, S. Savary, I. Savini, and M. Voltz. (2005). Pesticides, agriculture et environnement: Réduire l'utilisation des pesticides et en limiter les impacts environnementaux. Rapport d'expertise réalisé par l'INRA et le Cemagref à la demande du Ministère de l'agriculture et de la pêche (MAP) et du Ministère de l'écologie et du développement durable (MEDD)

Bazoche, P., F. Bunte, P. Combris, E. Giraud-Héraud, A. Seabra-Pinto, and E. Tsakiridou. (2013). Willingness to pay for pesticides' reduction in EU: nothing but organic? European review of Agricultural Economics 41(1):87-109.

Becker, G.M., M.H. DeGroot, and J. Marschak. (1964). Measuring utility by a single-response sequential method. Behavioral Science 9(3):226-232.

Boxall, P., W.L. (Vic) Adamowicz, and A. Moon. (2009). Complexity in choice experiments: choice of the status quo alternative and implications for welfare measurement. Australian Journal of Agricultural and Resource Economics 53(4):503-519.

Canali, G. (2011). The role of the 'integrated production' scheme in the fruit and vegetable CMO. In A. Sorrentino, R. Henke, and S. Severini, eds. The common agricultural policy after the Fischler reform. Farnham, England: Ashgate, pp. 417-430.

Carlsson, F., P. Frykblom, and C.J. Lagerkvist. (2007). Consumer willingness to pay for farm animal welfare: mobile abattoirs versus transportation to slaughter. European Review of Agricultural Economics 34(3):321-344. 
Carson, R.T., J.J. Louviere, D.A. Anderson, P. Arabie, D.S. Bunch, D.A. Hensher, R.M. Johnson, W.F. Kuhfeld, D. Steinberg, J. Swait, H. Timmermans, and J.B. Wiley. (1994). Experimental analysis of choice. Marketing Letters 5(4):351-367.

Chatfield, M., and A. Mander. (2009). The Skillings-Mack test (Friedman test when there are missing data). The Stata Journal 9(2):299-305.

Corrigan, J.R., D.P.T. Depositario, R.M. Nayga, X. Wu, and T.P. Laude. (2009). Comparing Open-Ended Choice Experiments and Experimental Auctions: An Application to Golden Rice. American Journal of Agricultural Economics 91(3):837-853.

EU. (2009). Directive 2009/128/EC of the European Parliament and of the Council of 21 October 2009 establishing a framework for Community action to achieve the sustainable use of pesticides.

Fischbacher, U. (2007). z-Tree: Zurich Toolbox for Ready-made Economic Experiments. Experimental Economics 10(2):171-178.

Florax, R., C.M. Travisi, and P. Nijkamp. (2005). A meta-analysis of the willingness to pay for reductions in pesticide risk exposure. European review of Agricultural Economics 32(4):441-467.

Ginon, E., G. Ares, L.H. Esteves dos Santos Laboissière, J. Brouard, S. Issanchou, and R. Deliza. (2014). Logos indicating environmental sustainability in wine production: An exploratory study on how do Burgundy wine consumers perceive them. Food Research International 62:837-845.

Ginon, E., C. Chabanet, P. Combris, and S. Issanchou. (2014). Are decisions in a real choice experiment consistent with reservation prices elicited with BDM 'auction'? The case of French baguettes. Food Quality and Preference 31:173-180.

Grolleau, G., A. Sutan, and R. Vranceanu. (2013). Taking the Well-Being of Future Generations Seriously: Do People Contribute More to Intra-temporal or Inter-temporal Public Goods? ESSEC Working Paper 1313.

Hasund, K.P., M. Kataria, and C.J. Lagerkvist. (2011). Valuing public goods of the agricultural landscape: a choice experiment using reference points to capture observable heterogeneity. Journal of Environmental Planning and Management 54(1):31-53.

Hensher, D.A. (2010). Hypothetical bias, choice experiments and willingness to pay. Transportation Research Part B: Methodological 44(6):735-752.

Hu, W., M. Veeman, W. Adamowicz, and G. Gao. (2006). Consumers' Food Choices with Voluntary Access to Genetic Modification Information. Canadian Journal of Agricultural Economics 54(4):585-604.

Jumbe, C.B.L., and A. Angelsen. (2011). Modeling choice of fuelwood source among rural households in Malawi: A multinomial probit analysis. Energy Economics 33(5):732738.

Kallas, Z., C. Escobar, and J.M. Gil. (2012). Assessing the impact of a Christmas advertisement campaign on Catalan wine preference using Choice Experiments. Appetite 58(1):285- 
Lamine, C. I. Haynes, M. Barzman, R. Paratte. (2010). The potential role of supermarket procurement strategies as drivers of IPM. ENDURE Policy Brief No. 2.

Lancaster, K.J. (1966). A New Approach to Consumer Theory. Journal of Political Economy 74(2):132-157.

Lefebvre, M., S.R.H. Langrell, and S. Gomez-y-Paloma. (2015). Incentives and policies for integrated pest management in Europe: a review. Agronomy for Sustainable Development 35(1):27-45

Lusk, J.L., and T.C. Schroeder. (2004). Are Choice Experiments Incentive Compatible? A Test with Quality Differentiated Beef Steaks. American Journal of Agricultural Economics 86(2):467-482.

Marette, S., A. Messéan, and G. Millet. (2012). Consumers' willingness to pay for eco-friendly apples under different labels: Evidences from a lab experiment. Food Policy 37:151161.

Maynard, L.J., J.G. Hartell, A.L. Meyer, and J. Hao. (2004). An experimental approach to valuing new differentiated products. Agricultural Economics 31(2-3):317-325.

Mc Fadden, D.L. (1973). Conditional Logit Analysis of Qualitative Choice Behavior. In P. Zarembka (Ed.), Frontiers in Econometrics (pp. 105-142). Academic Press: New York

Mesías Díaz, F.J., F. Martínez-Carrasco Pleite, J.-M. Martínez Paz, and P. Gaspar García. (2012). Consumer knowledge, consumption, and willingness to pay for organic tomatoes. British Food Journal 114(3):318-334.

Michaud, C., D. Llerena, and I. Joly. (2012). Willingness to pay for environmental attributes of non-food agricultural products: a real choice experiment. European Review of Agricultural Economics 40(2):313-329.

Miettinen, A., R. Hietala-Koivu, and H. Lehtonen. (2004). On diversity effects of alternative agricultural policy reforms in Finland: An agricultural sector modelling approach. Agricultural and food science 13:229-246.

Morris, C., and M. Winter. (1999). Integrated farming systems: the third way for European agriculture? Land Use Policy 16(4):193-205.

Mouron, P., B. Heijne, A. Naef, J. Strassemeyer, F. Hayer, J. Avilla, A. Alaphilippe, H. Höhn, J. Hernandez, G. Mack, G. Gaillard, J. Solé, B. Sauphanor, A. Patocchi, J. Samietz, E. Bravin, C. Lavigne, M. Bohanec, B. Golla, C. Scheer, U. Aubert, and F. Bigler. (2012). Sustainability assessment of crop protection systems: SustainOS methodology and its application for apple orchards. Agricultural Systems 113(0):1-15.

Pelzer, E., G. Fortino, C. Bockstaller, F. Angevin, C. Lamine, C. Moonen, V. Vasileiadis, D. Guérin, L. Guichard, R. Reau, and A. Messéan. (2012). Assessing innovative cropping systems with DEXiPM, a qualitative multi-criteria assessment tool derived from DEXi. Ecological Indicators 18(0):171-182.

Rege, M., and K. Telle. (2004). The impact of social approval and framing on cooperation in public good situations. Journal of Public Economics 88(7-8):1625-1644. 
Rigby, D., F. Alcon, and M. Burton. (2010). Supply uncertainty and the economic value of irrigation water. European Review of Agricultural Economics 37(1):97-117.

Train, K.E. (2009). Discrete Choice Methods with Simulation. 2nd ed. Cambridge University Press.

Vasileiadis, V.P., M. Sattin, S. Otto, A. Veres, Z. Pálinkás, R. Ban, X. Pons, P. Kudsk, R. van der Weide, E. Czembor, A.C. Moonen, and J. Kiss. (2011). Crop protection in European maize-based cropping systems: Current practices and recommendations for innovative Integrated Pest Management. Agricultural Systems 104(7):533-540.

van der Velden, N., R. Suay, A. Urbaneja, M. Giorgini, M. Ruoco, C. Poncet, and A. Lefèvre. (2012). Recent developments and market opportunities for IPM in greenhouse tomatoes in southern Europe: consequences for advanced IPM toolboxes and greenhouse engineering. Research report LEI memorandum 12-077, Wageningen; UR

Weaver, R.D., D.J. Evans, and A.E. Luloff. (1992). Pesticide use in tomato production: Consumer concerns and willingness-to-pay. Agribusiness 8(2):131-142.

Wibberley, J. (1995). Cropping intensity and farming systems: integrity and intensity in international perspective. Journal of the Royal Agricultural Society of England 156:4355.

Wier, M., and C. Calverley. (2002). Market potential for organic foods in Europe. British Food Journal 104(1):45-62.

Yiridoe, E.K., S. Bonti-Ankomah, and R.C. Martin. (2002). Comparison of consumer perceptions and preference toward organic versus conventionally produced foods: A review and update of the literature. Renewable Agriculture and Food Systems 20(4):193-205.

Yue, C., F. Alfnes, and H.H. Jensen. (2009). Discounting spotted apples: investigating consumers' willingness to accept cosmetic damage in an organic product. Journal of Agricultural and Applied Economics 41(1):29-46. 
Table 1: Description of each round of the experimental design

For each round, the variable modified compared to previous rounds is in bold. Changes in consumption patterns are interpreted as the impact of this variable.

\begin{tabular}{|c|c|c|c|c|}
\hline Rounds & Products & $\begin{array}{l}\text { Information } \\
\text { available } \\
\text { (see appendix) }\end{array}$ & $\begin{array}{l}\text { Prices } \\
\text { (see Table 2) }\end{array}$ & $\begin{array}{l}\text { Treatment effect } \\
\text { measured }\end{array}$ \\
\hline 1 & $\begin{array}{l}3 \text { conventional } \\
\text { (conv-R, conv- } \\
\text { VA, conv-VB) } \\
1 \text { organic } \\
1 \text { IPM }\end{array}$ & Type of agriculture & Reference & Baseline \\
\hline 2 & $\begin{array}{l}3 \text { conventional } \\
\text { (conv-R, conv- } \\
\text { VA, conv-VB) } \\
1 \text { organic } \\
1 \text { IPM }\end{array}$ & $\begin{array}{l}\text { Type of agriculture } \\
+\quad \text { upon-request: } \\
\text { More information } \\
\text { on the production } \\
\text { system }\end{array}$ & Reference & $\begin{array}{l}\text { Impact of more } \\
\text { information on the } \\
\text { production system } \\
\text { compared to } \\
\text { round } 1\end{array}$ \\
\hline 3 & $\begin{array}{l}3 \text { conventional } \\
\text { (conv-R, conv- } \\
\text { VA, conv-VB) } \\
1 \text { organic } \\
1 \mathrm{IPM}\end{array}$ & $\begin{array}{l}\text { Type of agriculture } \\
+\quad \text { upon-request: } \\
\text { More information on } \\
\text { the production } \\
\text { system }\end{array}$ & List 2 & $\begin{array}{l}\text { Impact of price } \\
\text { compared } \\
\text { round } 2\end{array}$ \\
\hline 4 & $\begin{array}{l}3 \text { conventional } \\
\text { (conv-R, conv- } \\
\text { VA, conv-VB) } \\
1 \text { organic } \\
1 \text { IPM }\end{array}$ & $\begin{array}{l}\text { Type of agriculture } \\
+\quad \text { upon-request: } \\
\text { More information on } \\
\text { the production } \\
\text { system }\end{array}$ & List 3 & $\begin{array}{l}\text { Impact of price } \\
\text { compared to } \\
\text { round } 2 \text { and } 3\end{array}$ \\
\hline 5 & $\begin{array}{l}3 \text { conventional } \\
\text { (conv-R, conv- } \\
\text { VA, conv-VB) } \\
1 \text { organic } \\
1 \text { IPM }\end{array}$ & $\begin{array}{l}\text { Type of agriculture } \\
+\quad \text { upon-request: } \\
\text { More information on } \\
\text { the production } \\
\text { system } \\
+ \text { upon-request: } \\
\text { More info on the } \\
\text { characteristics of } \\
\text { the final product }\end{array}$ & List 2 & $\begin{array}{l}\text { Impact of more } \\
\text { information on the } \\
\text { characteristics of } \\
\text { the final product } \\
\text { compared to } \\
\text { round } 3\end{array}$ \\
\hline 6 & $\begin{array}{l}3 \text { conventional } \\
\text { (conv-R, conv- } \\
\text { VA, conv-VB) } \\
1 \text { organic } \\
1 \text { IPM }\end{array}$ & $\begin{array}{l}\text { Type of agriculture } \\
+\quad \text { upon-request: } \\
\text { More information on } \\
\text { the production } \\
\text { system }\end{array}$ & List 3 & $\begin{array}{l}\text { Impact of more } \\
\text { information on the } \\
\text { characteristics of } \\
\text { the final product } \\
\text { compared to } \\
\text { round } 4\end{array}$ \\
\hline
\end{tabular}




\begin{tabular}{|c|c|c|c|c|}
\hline & & $\begin{array}{l}+\quad \text { upon-request: } \\
\text { More info on the } \\
\text { characteristics of the } \\
\text { final product }\end{array}$ & & $\begin{array}{l}\text { Impact of price } \\
\text { compared } \\
\text { round } 5\end{array}$ \\
\hline $\begin{array}{l}\text { Information } \\
\text { step }\end{array}$ & \multicolumn{4}{|c|}{$\begin{array}{l}\text { Messages justifying the change in the shelf space dedicated to IPM from } 1 / 5 \\
\text { to } 1 / 3 \text { (see appendix) }\end{array}$} \\
\hline 7 & $\begin{array}{l}1 \text { conventional } \\
\text { (conv-VA) } \\
1 \text { organic } \\
1 \text { IPM } \\
\end{array}$ & $\begin{array}{l}\text { Full disclosure of } \\
\text { information to all }\end{array}$ & List 2 & $\begin{array}{l}\text { Impact of shelf } \\
\text { space compared to } \\
\text { round } 5\end{array}$ \\
\hline 8 & $\begin{array}{l}1 \text { conventional } \\
(\text { conv-VA) } \\
1 \text { organic } \\
1 \text { IPM }\end{array}$ & $\begin{array}{l}\text { Full disclosure of } \\
\text { information to all }\end{array}$ & List 3 & $\begin{array}{l}\text { Impact of shelf } \\
\text { space compared to } \\
\text { round } 6 \\
\text { Impact of price } \\
\text { compared } \\
\text { round } 7\end{array}$ \\
\hline $\begin{array}{l}\text { Information } \\
\text { step }\end{array}$ & \multicolumn{4}{|c|}{$\begin{array}{l}\text { Messages justifying the change in the shelf space dedicated to IPM from } 1 / 3 \\
\text { to } 1 / 2 \text { (see appendix) }\end{array}$} \\
\hline 9 & $\begin{array}{l}1 \text { organic } \\
1 \text { IPM }\end{array}$ & $\begin{array}{l}\text { Full disclosure of } \\
\text { information to all }\end{array}$ & List 2 & $\begin{array}{l}\text { Impact of shelf } \\
\text { space compared to } \\
\text { round } 5 \text { and } 7\end{array}$ \\
\hline 10 & $\begin{array}{l}1 \text { organic } \\
1 \text { IPM }\end{array}$ & $\begin{array}{l}\text { Full disclosure of } \\
\text { information to all }\end{array}$ & List 3 & $\begin{array}{l}\text { Impact of shelf } \\
\text { space compared to } \\
\text { round } 6 \text { and } 8 \\
\text { Impact of price } \\
\text { compared to } \\
\text { round } 9\end{array}$ \\
\hline
\end{tabular}


Table 2: Posted prices list summer/autumn (Euros/kg)

\begin{tabular}{|l|l|l|c|c|c|c|c|}
\hline & $\begin{array}{l}\text { Prices list } \\
\text { (euros) }\end{array}$ & Conv-R & $\begin{array}{c}\text { Conv- } \\
\text { VA }\end{array}$ & $\begin{array}{c}\text { Conv- } \\
\text { VB }\end{array}$ & Organic & IPM & $\begin{array}{c}\text { Price } \\
\text { difference } \\
\text { (Organic- } \\
\text { IPM) }\end{array}$ \\
\hline \multirow{2}{*}{ Summer } & Reference & 1.5 & 1.9 & 2 & 2.6 & 2.2 & 0.4 \\
\cline { 2 - 8 } & List 2 & 1.1 & 1.7 & 1.8 & 3 & 2.4 & 0.6 \\
\cline { 2 - 8 } & List 3 & 1.5 & 1.6 & 1.7 & 2.6 & 2.5 & 0.1 \\
\hline \multirow{2}{*}{ Autumn } & Reference & 1.5 & 2 & 2.2 & 3 & 2.5 & 0.5 \\
\cline { 2 - 8 } & List 2 & 1.1 & 1.8 & 2 & 3.4 & 2.7 & 0.7 \\
\cline { 2 - 8 } & List 3 & 1.5 & 1.6 & 1.7 & 2.6 & 2.5 & 0.1 \\
\hline
\end{tabular}

Table 3: Socio demographic characteristics and consumption habits of the participants

\begin{tabular}{lrrrr}
\hline & Mean & St Dev & Min & Max \\
\hline Percentage of female consumers in the sample & 68 & & & \\
\hline Age (years) & 39.48 & 14.85 & 22 & 75 \\
\hline Weekly consumption of tomatoes in winter $(\mathrm{kg})$ & 0.77 & 1.08 & 0 & 13 \\
\hline Weekly consumption of tomatoes in summer $(\mathrm{kg})$ & 2.20 & 1.71 & 0 & 10 \\
\hline Price usually paid for a kg of tomatoes $(€ / \mathrm{kg})$ & 1.98 & 0.74 & 0 & 6 \\
\hline Share of organic tomatoes in total consumption & 0.26 & 0.29 & 0 & 1 \\
\hline Per
\end{tabular}

Percentage of consumers in the sample never consuming organic tomatoes (the share of organic tomatoes in total consumption $=0$ )

Percentage of consumers in the sample only consuming organic tomatoes (the share of organic tomatoes in total consumption=1)

Table 4: Significance of the difference across rounds in the quantities purchased by each participant of each type of tomatoes (as observed in Figure 1)

\begin{tabular}{|c|c|c|c|c|c|c|c|c|c|c|c|c|c|}
\hline & Rounds & $1-2$ & $2-3$ & $3-4$ & $3-5$ & $4-6$ & $5-6$ & $5-7$ & $6-8$ & $7-8$ & $7-9$ & $8-10$ & $9-10$ \\
\hline \multirow[t]{3}{*}{ Impact of prices } & Conventional & & $* * *$ & $* * *$ & & & $* * *$ & & & n.s. & & & \\
\hline & Organic & & $* * *$ & $* * *$ & & & $* * *$ & & & $* * *$ & & & $* * *$ \\
\hline & IPM & & $* * *$ & $* * *$ & & & $* * *$ & & & $* * *$ & & & $* * *$ \\
\hline \multirow{3}{*}{$\begin{array}{l}\text { Impact of shelf } \\
\text { space dedicated } \\
\text { to IPM }\end{array}$} & Conventional & & & & & & & $* * *$ & $* * *$ & & & & \\
\hline & Organic & & & & & & & $* * *$ & $* * *$ & & $* * *$ & $* * *$ & \\
\hline & IPM & & & & & & & $* * *$ & $* * *$ & & $* * *$ & n.s. & \\
\hline \multirow{3}{*}{$\begin{array}{ll}\text { Impact } & \text { of } \\
\text { information } & \\
\text { disclosure } & \end{array}$} & Conventional & $* * *$ & & & $* *$ & $* * *$ & & & & & & & \\
\hline & Organic & $* * *$ & & & $* * *$ & $* * *$ & & & & & & & \\
\hline & IPM & $* * *$ & & & $* *$ & $* * *$ & & & & & & & \\
\hline
\end{tabular}

Note: "n.s." denotes non-significant difference, * denotes significant difference at $10 \%$, ** denotes significant difference at $5 \%$ and $* * *$ denotes significant difference at $1 \%$ as tested by the Wilcoxon matched-pairs signed-ranks test. 
Table 5: Coding of the variables in the multinomial probit model

\begin{tabular}{|l|l|}
\hline \multicolumn{1}{|c|}{ Variable } & \multicolumn{1}{c|}{ Definition } \\
\hline price & Price of the tomatoes \\
\hline shelf-space & Shelf space dedicated to the product in \% \\
\hline Info1 & $=1$ if the participant is informed on the production system of the product \\
\hline Info2 & $\begin{array}{l}\text { terms of residues, on top of being informed on the production system of the } \\
\text { product }\end{array}$ \\
\hline female & $=1$ if the participant is a female \\
\hline age & In years \\
\hline kgweek_nov & Weekly consumption of tomatoes in November (per kg) \\
\hline usualprice & Price usually paid by the participant for tomatoes \\
\hline halforganic & $\begin{array}{l}=1 \text { if more than half of the usual tomatoes consumption of the participant is } \\
\text { organic }\end{array}$ \\
\hline PEM & $=1$ for sessions with the price endogeneity mechanism \\
\hline order_ICCOC & $\begin{array}{l}=1 \text { if the order of presentation of the products in the first rounds is IPM- } \\
\text { Conventional- Conventional-Organic-Conventional (omitted) }\end{array}$ \\
\hline order_CICOC & $\begin{array}{l}=1 \text { if the order of presentation of the products in the first rounds is Conventional- } \\
\text { IPM-conventional-Organic-Conventional }\end{array}$ \\
\hline order_CCIOC & $\begin{array}{l}=1 \text { if the order of presentation of the products in the first rounds is Conventional- } \\
\text { Conventional-IPM-Organic- Conventional }\end{array}$ \\
\hline order_COCIC & $\begin{array}{l}\text { =1 if the order of presentation of the products in the first rounds is Conventional- } \\
\text { Organic-Conventional-IPM-Conventional }\end{array}$ \\
\hline order_CCCOI & $\begin{array}{l}=1 \text { if the order of presentation of the products in the first rounds is Conventional- } \\
\text { Conventional- Conventional-Organic-IPM }\end{array}$ \\
\hline
\end{tabular}


Table 6: Alternative-specific multinomial probit - estimates

\begin{tabular}{|c|c|c|c|}
\hline VARIABLES & & $\begin{array}{l}\text { Probability to } \\
\text { choose } \\
\text { conventional } \\
\text { relative to IPM }\end{array}$ & $\begin{array}{l}\text { Probability to } \\
\text { choose organic } \\
\text { relative to IPM }\end{array}$ \\
\hline \multirow[t]{2}{*}{ female } & & -0.264 & -0.109 \\
\hline & & $(0.189)$ & $(0.076)$ \\
\hline \multirow[t]{2}{*}{ age } & & 0.002 & $0.004 * *$ \\
\hline & & $(0.006)$ & $(0.002)$ \\
\hline \multirow[t]{2}{*}{ kgweek_nov } & & -0.058 & -0.036 \\
\hline & & $(0.064)$ & $(0.025)$ \\
\hline \multirow[t]{2}{*}{ usualprice } & & -0.176 & 0.047 \\
\hline & & $(0.140)$ & $(0.047)$ \\
\hline \multirow[t]{2}{*}{ halforganic } & & $-0.894 * * *$ & $0.384 * *$ \\
\hline & & $(0.249)$ & $(0.150)$ \\
\hline \multirow[t]{2}{*}{ PEM } & & -0.106 & 0.010 \\
\hline & & $(0.183)$ & $(0.059)$ \\
\hline \multirow[t]{2}{*}{ order_CCIOC } & & 0.470 & -0.053 \\
\hline & & $(0.293)$ & $(0.099)$ \\
\hline \multirow[t]{2}{*}{ order_COCIC } & & -0.317 & 0.034 \\
\hline & & $(0.314)$ & $(0.086)$ \\
\hline \multirow{2}{*}{ order_CCCOI } & & 0.100 & 0.022 \\
\hline & & $(0.320)$ & $(0.089)$ \\
\hline \multirow[t]{2}{*}{ order_CICOC } & & 0.380 & -0.090 \\
\hline & & $(0.289)$ & $(0.093)$ \\
\hline \multirow[t]{2}{*}{ price } & $-0.773 * * *$ & & \\
\hline & $(0.222)$ & & \\
\hline \multirow[t]{2}{*}{ shelf-space } & $0.031 * * *$ & & \\
\hline & $(0.003)$ & & \\
\hline \multirow[t]{2}{*}{ Info1 } & $0.284 * *$ & & \\
\hline & $(0.139)$ & & \\
\hline \multirow[t]{2}{*}{ Info2 } & 0.162 & & \\
\hline & $(0.105)$ & & \\
\hline \multirow[t]{2}{*}{ Constant } & & $-1.239 * * *$ & 0.060 \\
\hline & & $(0.470)$ & $(0.136)$ \\
\hline$\theta_{23}^{*}$ & $-0.766^{* *}$ & & \\
\hline$\theta_{33}^{*}$ & 0.003 & & \\
\hline Observations & 5,292 & & \\
\hline $\begin{array}{l}\text { Log simulated- } \\
\text { pseudolikelihood }\end{array}$ & -1621.6441 & & \\
\hline Wald chi2(24) & 152.27 & & \\
\hline Prob > chi2 & 0.0000 & & \\
\hline & $\begin{array}{r}* * * \mathrm{p}<0.01 \\
\text { Robust standa }\end{array}$ & $\begin{array}{l}05, * p<0.1 \\
\text { in parentheses }\end{array}$ & \\
\hline
\end{tabular}


Table 7: Alternative-specific multinomial probit -marginal effects at means

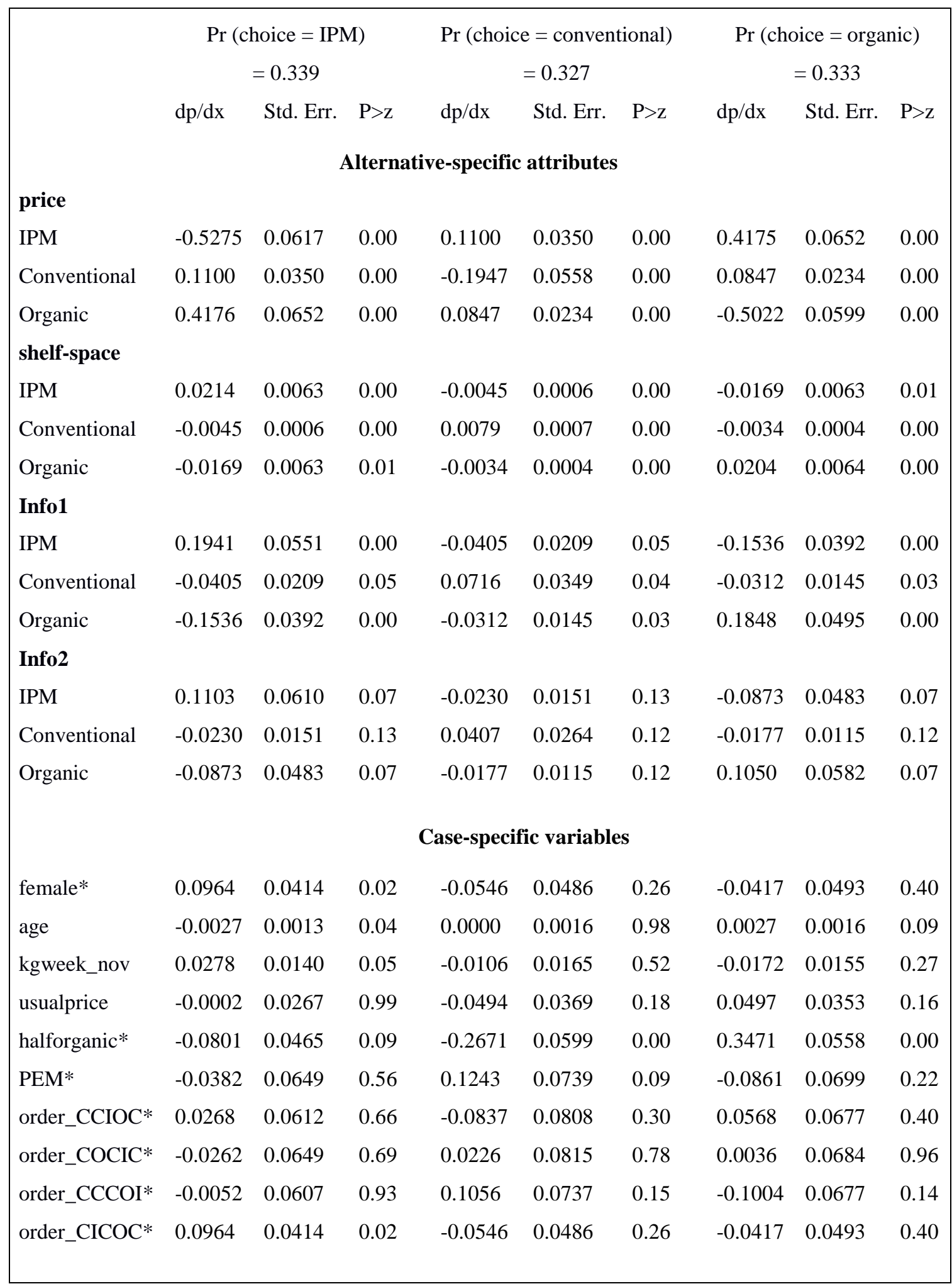

(*) dp/dx is for discrete change of indicator variable from 0 to 1 
Figure 1: Market share of IPM and organic and conventional tomatoes by round $(n=189$, all 10 sessions)

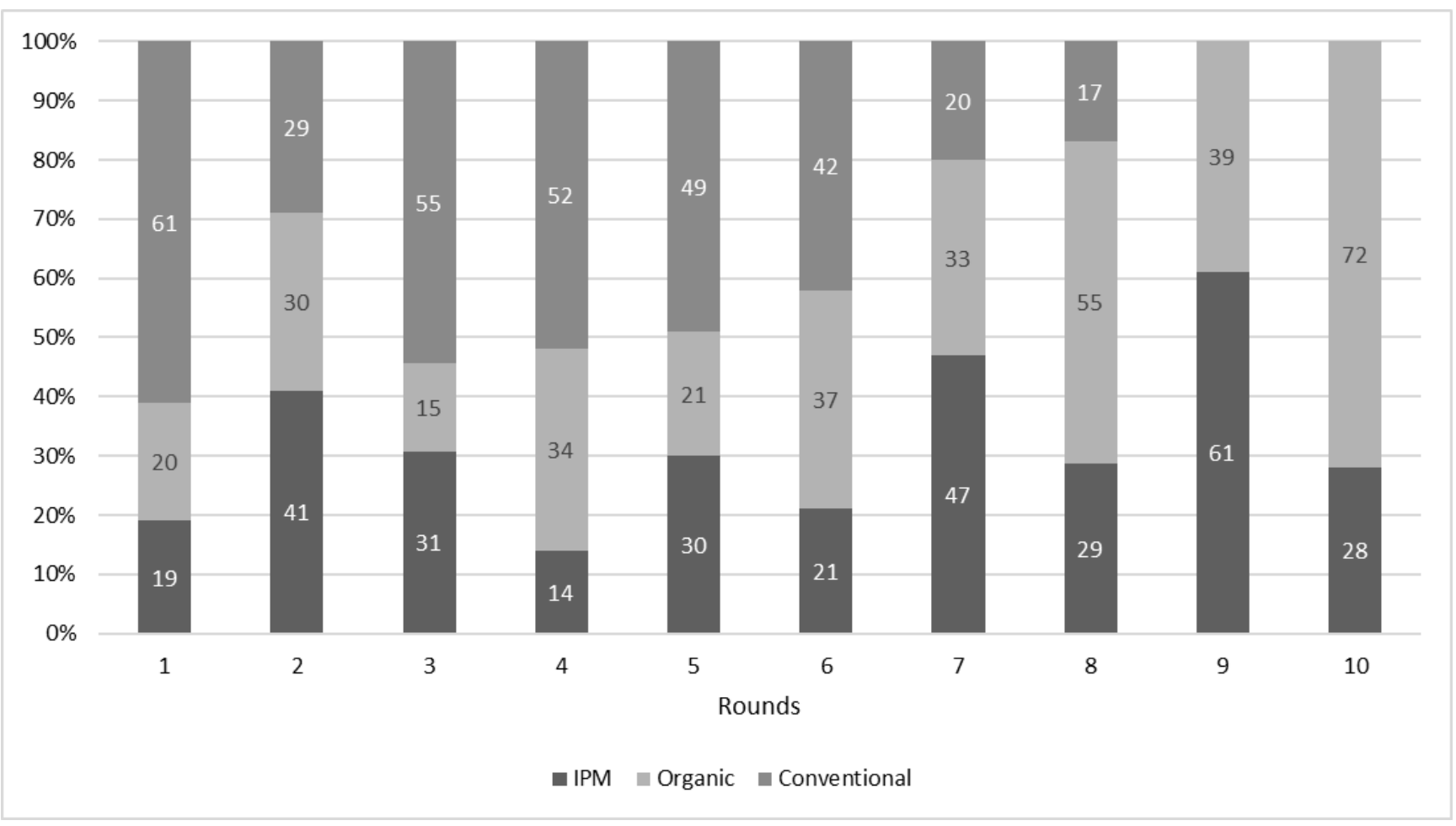

Figure 2: Level of information of participants before full disclosure of the information to all participants (round 6)

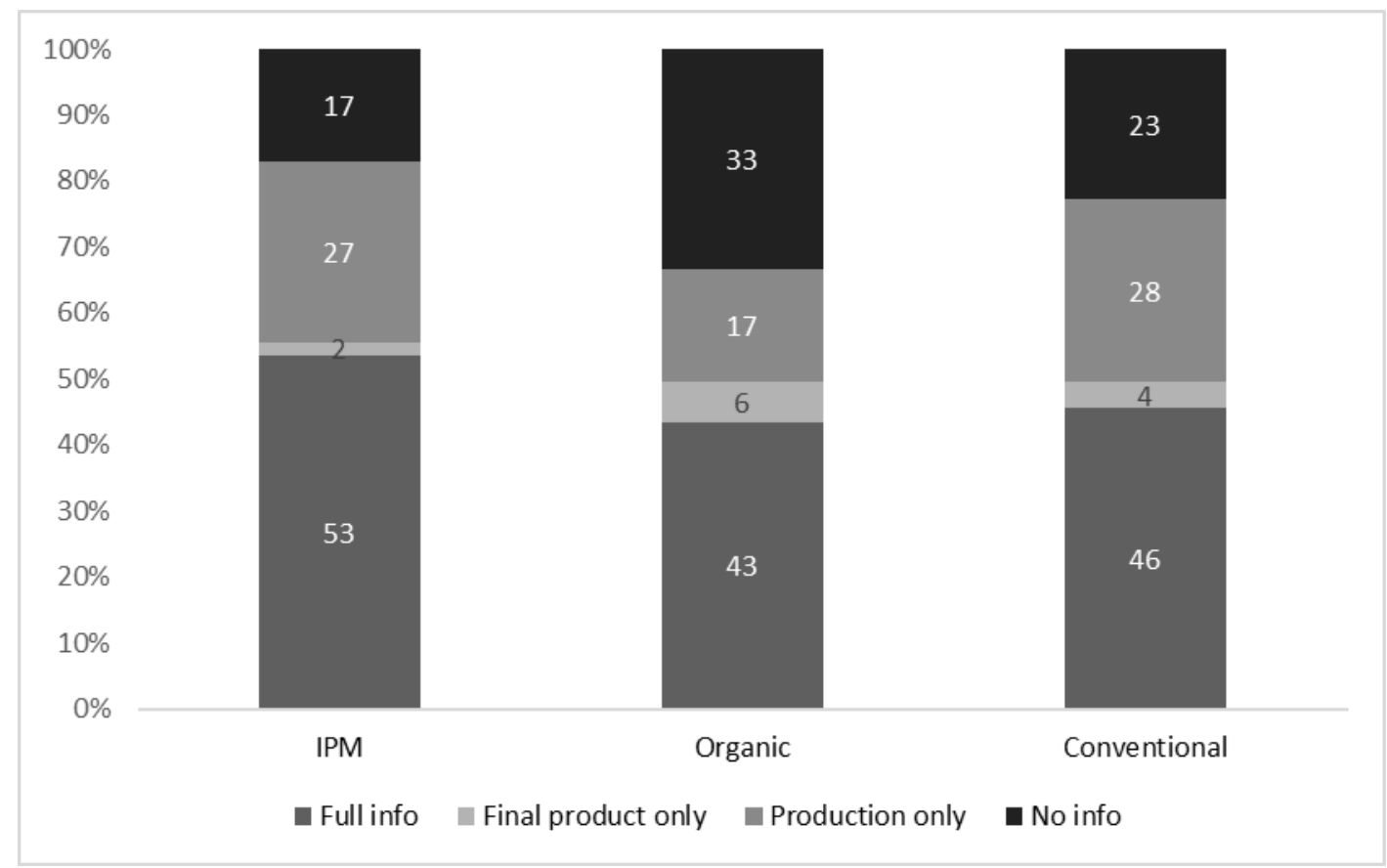




\section{Appendix: Instructions (translation from French version)}

You are participating in an experiment to analyse consumers' preferences towards certain types of products. The sum of $€ 20$ which was given to you upon arrival is yours. You can use it as you wish during the experiment, specifically to buy the products that are available for sale.

To ensure anonymity, you are identified by a code. All information collected about your decisions will be confidential.

During the experiment, you are asked not to communicate with other participants. If you have a question, please speak directly to the lab manager.

Note that you do not have to eat any product during this experience.

In this experiment, you will have the opportunity to make purchases of products. You will have several opportunities to purchase products. Each opportunity will be called a "round".

Each round takes place in the same way: you will be given information on several products for sale (price, and other characteristic(s)).

The following procedure will be repeated for each round:

Step 1: Product information (price, other information)

Step 2: Desire to purchase one of the products

Reading some additional associated pieces of information is optional. You are free to read if you want by clicking on the optional buttons.

Note: For each round, you can choose only one product among those proposed.

Once all rounds have been completed, one of them will be drawn at random. Buyers of this round will each receive the product purchased and will pay the market price. For all other rounds, buyers will not receive the product and will not have to make any payments.

Once all rounds are completed, you will have to answer a short questionnaire.

[only for the treatment "price endogeneity mechanism"]: Through your decisions, you can influence the price of the tomatoes for the consumers who will take part in the following experimental sessions: the more consumers buy organic or integrated tomatoes, the lower their prices in the following experimental sessions. 


\section{Printscreen: example for round 5}

\section{Round 5}

Choose one type of tomatoes and specify the quantity you would like to buy (in $\mathrm{kg}$ ) (You can indicate a quantity with a decimal. For example : $0.5 \mathrm{~kg}$.)

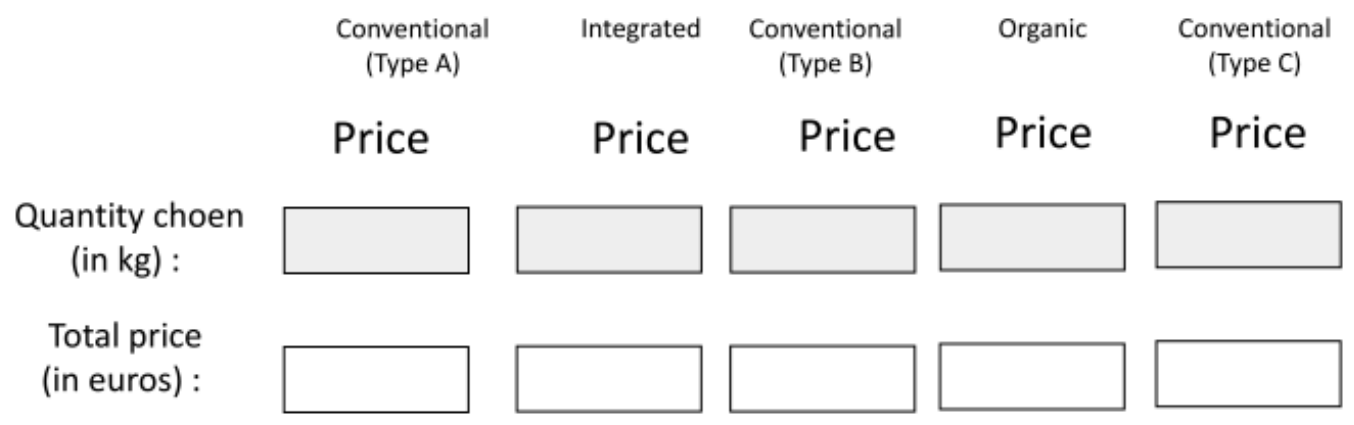

More information on the production system :

More information on the characteristics of the final product

\section{Conventional}

Conventional

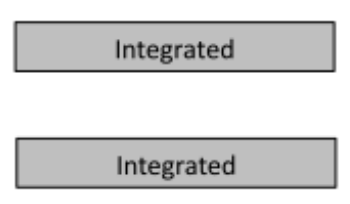

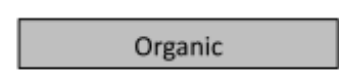

Organic

\section{Information visible on the computer screen}

Information available to participants upon request when clicking on "More information on the production system: conventional"

Crop protection has a key role in agriculture since it protects crops from weeds, diseases and pest which are major causes of yield losses. Many crop protection methods exist (chemical pesticides, choice of crop varieties, soil management, use of beneficial insects...) and are used according to the crop protection strategy chosen by the farmer.

In conventional farming, chemical pesticides are used systematically and routinely for crop protection. It is the kind of crop protection which dominated the 20th century and which accounts for most farming today.

Tomatoes from conventional farming receive on average 30-35 spraying during the growing season (average for soil-less tomatoes, which represent most of tomatoes production in conventional agriculture)

Information available to participants upon request when clicking on "More information on the production system: integrated"'

Crop protection has a key role in agriculture since it protects crops from weeds, diseases and pest which are major causes of yield losses. Many crop protection methods exist (chemical pesticides, choice of crop varieties, soil management, use of beneficial insects...) and are used according to the crop protection strategy chosen by the farmer.

Integrated Pest Management can be considered as a third-way between conventional and organic crop protection strategies: the use of chemical pesticides is not prohibited but limited, 
thanks to a more efficient and targeted spraying and to the use of other methods (physical protection, organic protection, cultural practices ...).

Many tomatoes are produced nowadays with integrated pest management but the information is rarely disclosed in supermarkets.

Spraying of tomatoes is reduced to less than 5 per growing season with integrated pest management. This is less than in conventional farming but more than in organic (average for soil-less tomatoes, which represent a large majority of the tomatoes produced with integrated pest management).

Information available to participants upon request when clicking on "More information on the production system: organic"

Crop protection has a key role in agriculture since it protects crops from weeds, diseases and pest which are major causes of yield losses. Many crop protection methods exist (chemical pesticides, choice of crop varieties, soil management, use of beneficial insects...) and are used according to the crop protection strategy chosen by the farmer.

The specifications for organic farming totally prohibit the use of chemical pesticides. All organic tomatoes are soil- grown and with no chemical pesticides, contrarily to crop protection strategies used in conventional farming and integrated pest management.

Information available to participants upon request when clicking on "More information on the characteristics of the final product: conventional"

Pesticides tend to stay in fruits and vegetables, even after washing or peeling them. In order to protect consumers' health and promote good practices in farming, maximum residue levels have been set legally. It aims at avoiding that consumers eat more than the acceptable daily intake of the active substance. Fruits and vegetables with residue levels beyond this limit cannot be sold.

All conventional tomatoes contain less pesticide residues than the maximal limit imposed by regulation.

Information available to participants upon request when clicking on "More information on the characteristics of the final product: integrated"

Pesticides tend to stay in fruits and vegetables, even after washing or peeling them. In order to protect consumers' health and promote good practices in farming, maximum residue levels have been set legally. It aims at avoiding that consumers eat more than the acceptable daily intake of the active substance. Fruits and vegetables with residue levels beyond this limit cannot be sold.

Tomatoes produced according to Integrated Pest Management contain less pesticide residues than the maximal limit imposed by regulation, and, in average, 10 times less pesticides residues than what is observed in tomatoes from conventional production system.

Information available to participants upon request when clicking on "More information on the characteristics of the final product: organic"

Pesticides tend to stay in fruits and vegetables, even after washing or peeling them. In order to protect consumers' health and promote good practices in farming, maximum residue levels have 
been set legally. It aims at avoiding that consumers eat more than the acceptable daily intake of the active substance. Fruits and vegetables with residue levels beyond this limit cannot be sold.

Chemical pesticides not being authorized in organic farming, organic tomatoes can be considered as residue-free compare to conventional and IPM tomatoes.

However, some studies have revealed that residues can be found in organic tomatoes, since pesticides can have been used in neighbour fields or in the past in the same field.

Information disclosed to all participants between rounds 6 and 7

The European Union has decided that from 2014, all farmers will have to use Integrated Pest Management to protect their crops against pests and diseases. Crop protection strategy as currently used in conventional production system will therefore be prohibited from 2014. Since farmers are anticipating this change, we can already observe that the share of conventional tomatoes in total production is diminishing. There is now only one type of conventional tomatoes available, plus on type of IPM and one type of organic tomatoes.

$\underline{\text { Information disclosed to all participants between rounds } 8 \text { and } 9}$

Crop protection strategies used in conventional production system will be forbidden starting from 2014. From now, only IPM and organic tomatoes are available.

Photos of the experimental sessions

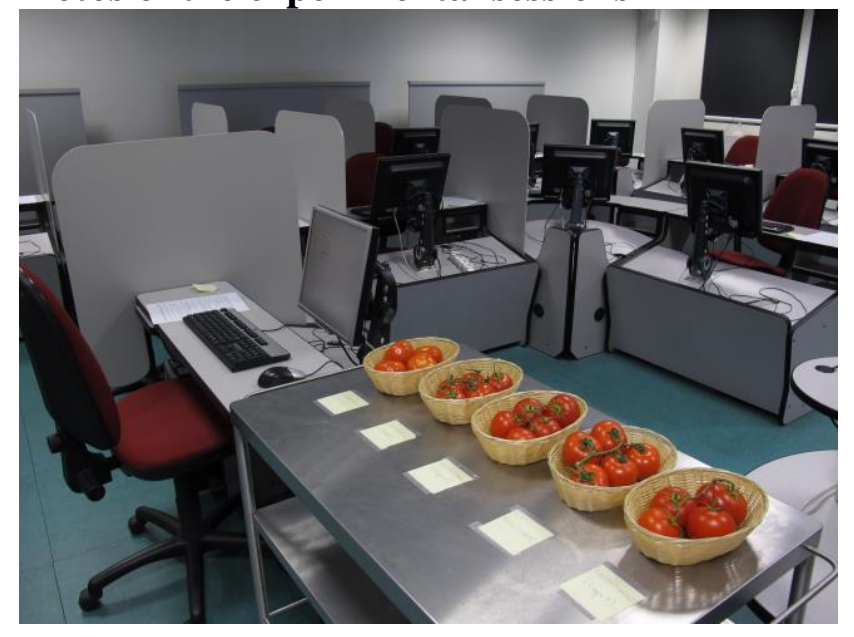

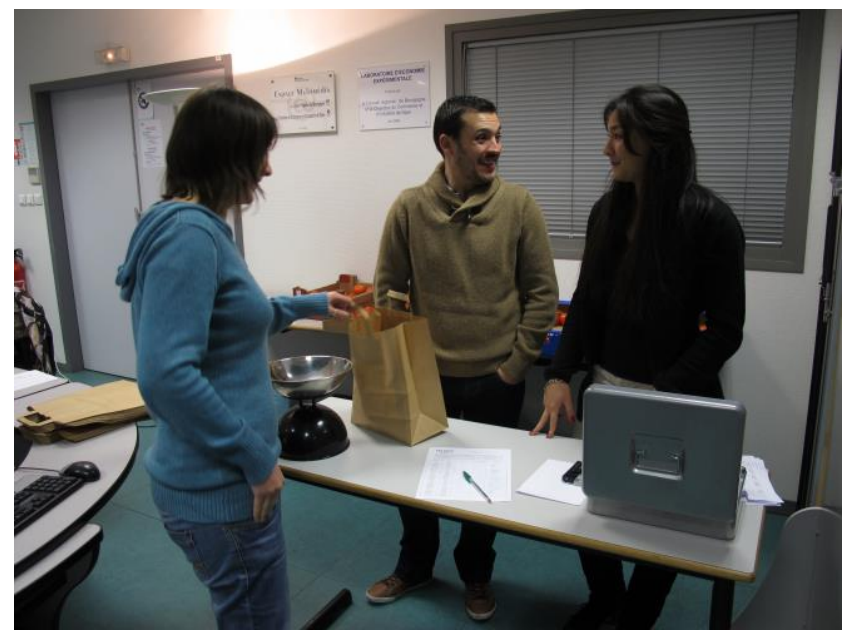

